\title{
N/S-co-doped porous carbon nanoparticles serving the dual- function of sulfur host and separator coating in Lithium-Sulfur batteries
}

\section{Noel Díez ${ }^{\star}$, Marta Sevilla and Antonio B. Fuertes}

Instituto de Ciencia y Tecnología del Carbono, INCAR-CSIC. Francisco Pintado Fe, 26. 33011 Oviedo, Spain

*Corresponding author: noel@incar.csic.es, abefu@incar.csic.es

\section{Abstract}

Porous carbon nanoparticles (PCN) co-doped with nitrogen and sulfur have been produced by applying a straightforward template-free method entailing a high-temperature reaction between polypyrrole nanoparticles and sodium thiosulfate. The activation process gives rise to porous carbon nanoparticles that combine several important properties: a) a uniform size of $\sim 80 \mathrm{~nm}$; b) a well-developed porosity with BET surface areas of up to $\sim 1700 \mathrm{~m}^{2} \mathrm{~g}^{-1}$ and pore volumes of up to $2.20 \mathrm{~cm}^{3} \mathrm{~g}^{-1}$; c) a sizeable $\mathrm{N}$ and $\mathrm{S}$ heteroatom content (of up to $2.7 \% \mathrm{~N}$ and $7.7 \% \mathrm{~S}$ ); and d) a good electrical conductivity (up to $3 \mathrm{~S} \mathrm{~cm}^{-1}$ ). The synthesis strategy offers a great versatility since two types of materials, PCN or S/PCN (nanocomposites comprising elemental sulfur infiltrated into the PCN), can be produced by introducing minor changes to the procedure. These materials have been tested on two components of a lithium-sulfur cell. The S/PCN nanocomposite is used as the cathode, whereas the PCN material is deposited onto the separator to form a thin packed layer in order to restrict the mobility of the polysulfides. Remarkably, the PCN coating layer notably enhances the utilization of sulfur (increase of $23 \%$ during the first cycles) and it provides robustness during long-term cycling. The battery assembled with these two components exhibits a highly stable cycling performance from the very first charge-discharge cycles, and delivers a reversible capacity of $841 \mathrm{mAh} \mathrm{g}^{-1}$ after 100 cycles at $0.2 \mathrm{C}$ with a coulombic efficiency of $99.3 \%$. Despite using a S/PCN composite with a high sulfur content ( $>70 \%$ ), the cell was successfully 
cycled at 2C over 500 charge-discharge cycles, and experienced a capacity decay of only $0.089 \%$ per cycle.

KEYWORDS: carbon nanoparticles, porous carbon, nitrogen and sulfur doping, lithium-sulfur battery, sulfur/carbon nanocomposite, polysulfides barrier.

\section{Introduction}

Lithium-sulfur (Li-S) batteries are one of the most promising rechargeable energy storage systems because of the low cost, environmentally-friendly nature and natural abundance of sulfur, as well as its high theoretical capacity $\left(1675 \mathrm{mAh} \mathrm{g}^{-1}\right)$ that can provide a high specific energy of $\sim 2600 \mathrm{Wh} \mathrm{kg}^{-1}(\sim$ five times higher than that of conventional Li-ion batteries). ${ }^{1-2}$ However, the viability of Li-S batteries is limited by the rapid capacity decay of the sulfur cathode, mainly due to the shuttle effect caused by the migration of intermediate soluble lithium polysulfides (LiPS). ${ }^{3}$

In order to improve the electrochemical performance of Li-S batteries, mitigation of the shuttle effect represents a serious challenge and, in consequence, much effort has been devoted to this problem. Thus, in recent literature numerous strategies centred on hampering the mobility of LiPS in order to restrict their access to the lithium anode have been reported. ${ }^{4} \mathrm{~A}$ wellknown procedure for restricting the mobility of LiPS consists in confining the sulfur inside the pores of conductive carbon hosts. ${ }^{5-6}$ In combination with this strategy, it has been verified that the doping of the porous carbon hosts with certain elements ( $N, \mathrm{O}, \mathrm{S}, \mathrm{B}$, etc.) serves to restrict the diffusion of LiPS because of the strong specific interactions between these heteroatoms and the soluble polysulfides. ${ }^{7}$ Furthermore, non-carbon inorganic sulfur hosts with polar 
surfaces, such as metal oxides, ${ }^{8-9}$ sulfides $^{9}$ or nitrides ${ }^{10}$ have also shown an ability to chemically block the shuttling of LiPS. Although the fabrication of sulfur cathodes according to the above strategies can reduce the mobility of LiPS, the capacity decay with cycling persists, highlighting the need for additional LiPS control schemes. A rational design of the sulfur cathode in combination with other measures to ensure a better control of the diffusion of LiPS appears to be the most appropriate strategy. To this end, much attention has been focused on the modification of other battery components (i.e. binder, separator or electrolyte). ${ }^{11-13}$ More specifically, the objective is to transform these elements into bifunctional systems so that, besides their specific purpose, they include an additional feature that contributes to supressing the mobility of LiPS.

The modification of pristine polypropylene (PP) separators is a simple and effective way to reduce the mobility of LiPS. ${ }^{13-15}$ Basically, it consists in coating the side of the separator facing the sulfur cathode with a layer of a functional material that impedes the diffusion of LIPs (obstruction) or, alternatively, exhibits a certain affinity towards soluble LiPS (adsorption). A variety of substances have been investigated with this purpose in mind: carbons, polymers (i.e. polypyrrole, polyaniline, Nafion, etc.), ${ }^{16-17} \mathrm{MOFs}^{18}$ or inorganic materials (i.e. oxides, silicates, sulfides, etc.) ${ }^{19-21}$ In particular, carbon coated separators have received much attention due to the unique physicochemical properties of carbon materials which combine a good electrical conductivity and chemical stability with an easy-to-design pore structure, morphology and particle size. The carbon particles deposited onto the separator not only serve as a barrier to obstruct/adsorb the LiPS dissolved in the electrolyte, but also as a second current collector that enhances the electronic accessibility of the 
active material. ${ }^{22} \mathrm{~A}$ plethora of carbon materials has been deposited onto the pristine PP separator, including graphene and graphene oxide sheets, ${ }^{23}$ carbon black, ${ }^{24}$ carbon nanofibers, ${ }^{25}$ carbon nanotubes, ${ }^{26}$ carbon capsules ${ }^{27}$ and a variety of porous carbons. Manthiram et al. were the first to report in 2014 the fabrication of bifunctional separators made up of a layer of carbon nanotubes ${ }^{28}$ or carbon black (super P) ${ }^{29}$ deposited onto one side of a PP separator. Although these non-polar and non-porous carbon materials can obstruct the diffusion of LiPS, their ability to adsorb polar LiPS is limited. In contrast, the deposition of a layer of porous carbon particles, besides acting as a physical barrier, will serve to adsorb a certain amount of soluble LiPS into the porous structure. To this end, a few authors have investigated the fabrication of PP separators coated with porous carbons particles, such as microporous carbon nanofibers ${ }^{30}$ or mesoporous carbons fabricated by means of nanocasting techniques based on the use of $\mathrm{SiO}_{2}{ }^{31}$ or $\mathrm{MgO}^{32}$ as sacrificial templates. It is important to note, however, that these carbon coatings increase the mass/volume of the separator, which translates into lower values of cell energy density. For this reason, the carbon loading and layer thickness need to be limited to values of $\sim 0.3 \mathrm{mg} \mathrm{cm}^{-2}$ and $<30 \mu \mathrm{m}$, respectively. These limitations imply that the size of the porous carbon particles needs to be around or below 1 $\mu \mathrm{m}$, which excludes the use of conventional porous carbons, what are usually made up of particles larger than $100 \mu \mathrm{m}$. However, the synthesis of porous carbon particles with a size $\leq 1 \mu \mathrm{m}$ is complex and usually requires the use of sacrificial templates. ${ }^{33-34}$

In the present paper, we report an easy template-free strategy for fabricating N,S-co-doped porous carbon nanoparticles smaller than $100 \mathrm{~nm}$. 
The nanoparticles will serve two purposes: i) as a barrier against LiPS and ii) as the sulfur host in the cathode. Accordingly, on the one hand, the N,S-co-doped porous carbon nanoparticles (PCN) were used to coat a side of the PP separator and construct a barrier to repress the mobility of soluble polysulfides, and on the other hand, sulfur-carbon nanocomposites made up of PCN nanoparticles loaded with controlled amounts of sulfur $(\sim 40-80 \%)$ were used to fabricate the sulfur cathodes. The PCN, synthesized using polypyrrole nanoparticles as carbon precursor, combine several suitable properties: a) a uniform diameter of around $80 \mathrm{~nm}$; b) a well-developed porosity (BET surface area $\sim 1600 \mathrm{~m}^{2} \mathrm{~g}^{-1}$ and pore volume $\sim 1.5-2.2 \mathrm{~cm}^{3} \mathrm{~g}^{-1}$ ) with a hierarchical pore structure made up of micropores and mesopores; c) a high electrical conductivity of $\sim 2-3 \mathrm{~S} \mathrm{~cm}^{-1}$; and d) a good packing density of $\sim 0.33-0.47 \mathrm{~g}$ $\mathrm{cm}^{-3}$. Furthermore, these carbon nanoparticles are co-doped with nitrogen and sulfur heteroatoms, which facilitates the retention of polar polysulfides. ${ }^{35-36}$ To fabricate the sulfur-PCN (S/PCN) hybrid nanoparticles, we used a procedure similar to that employed for PCN with a minor modification that includes the in situ generation and incorporation of elemental sulfur. This synthesis scheme allowed the production of PCN nanoparticles and the incorporation of the sulfur to be unified in a single process in accordance with our recently reported protocol. ${ }^{37}$ The S/PCN-based cathode with a high sulfur content $(>70 \%)$ coupled with the PCN-coated PP separator exhibited a notably improved electrochemical performance compared to the cell with the pristine separator. The PCN coating layer shows its effectiveness at two different levels: first, the conductive coating enhances the redox availability of the sulfur by lowering the cell resistance and acting as a second current collector; and secondly, its ideally 
suited pore structure and surface chemistry acts as an efficient barrier against polysulfides, thereby favouring a long-lasting battery cyclability.

\section{Experimental}

\section{Synthesis of the porous carbon nanoparticles (PCN).}

Polypyrrole nanoparticles (PPy) are the precursor of PCN and they were synthesized following the procedure reported by Lee et al. ${ }^{38}$ Briefly, $1.32 \mathrm{~g}$ of polyvinyl alcohol (MW 31,000, Aldrich) was dissolved in distilled water (400 mL) under vigorous stirring for $30 \mathrm{~min}$. Then, $29.9 \mathrm{~g}$ of $\mathrm{FeCl}_{3}$ (Aldrich) was added and the resulting $\mathrm{PVA} / \mathrm{FeCl}_{3}$ solution was stirred at a speed of $350 \mathrm{rpm}$ for $1 \mathrm{~h}$. Subsequently, $2.55 \mathrm{~g}$ of recently distilled pyrrole (Aldrich) was slowly added to the solution under continuous stirring. After $2 \mathrm{~h}$ of polymerization, the solid product was collected by centrifugation, washed several times with distilled water, re-dispersed in water and then, in order to avoid the agglomeration of polypyrrole nanoparticles, the water was removed by freeze-drying. The polypyrrole nanoparticles synthesised were thermally treated, under a $N_{2}$ atmosphere, up to $500^{\circ} \mathrm{C}(1 \mathrm{~h})$. This treatment resulted in a carbonization yield of around $70 \%$. The preparation of PCN samples was carried out by employing sodium thiosulfate as the activating agent. ${ }^{39}$ In a typical synthesis procedure, 1 $\mathrm{g}$ of pre-carbonized polypyrrole nanoparticles (PCPy) was mixed by handgrinding in a mortar with appropriate amounts of $\mathrm{KCl}$ (Aldrich) and $\mathrm{Na}_{2} \mathrm{~S}_{2} \mathrm{O}_{3}$ (Alfa-Aesar). The mass ratio of sodium thiosulfate to polypyrrole varied from 1.5 to 2.4, while the $\mathrm{KCl} / \mathrm{Na}_{2} \mathrm{~S}_{2} \mathrm{O}_{3}$ ratio was kept at 3.3. The resulting powder was heated under $\mathrm{N}_{2}$ up to $800{ }^{\circ} \mathrm{C}$ at a heating rate of $5^{\circ} \mathrm{C} \mathrm{min}{ }^{-1}$, and held at this temperature for $1 \mathrm{~h}$. Finally, the carbonized solid was washed with distilled water for several hours and the PCN sample was collected by filtration and 
dried at $120^{\circ} \mathrm{C}$. The carbon samples were denoted as PCN- $X$, where $X$ is the sodium thiosulfate-to-PPy mass ratio ( $X=1.5,2.0,2.2,2.3$ or 2.4$)$.

\section{Synthesis of the sulfur-carbon nanocomposites (S/PCN).}

The hybrid sulfur-carbon nanoparticles were synthesized following a procedure similar to that used for $\mathrm{PCN}$ except that, after the thermal treatment at $800{ }^{\circ} \mathrm{C}$, the carbonized solid was immersed in $\mathrm{HCl}(5 \mathrm{M})$ for $15 \mathrm{~h}$ under continuous stirring. The resulting S/PCN nanocomposites were washed with deionized water for several hours, collected by filtration and dried at $100^{\circ} \mathrm{C}$. The amount of infiltrated sulfur was determined by heat treatment of a portion of the composites up to $600{ }^{\circ} \mathrm{C}$ in a $\mathrm{N}_{2}$ atmosphere. The sulfur-carbon composites were labelled as S/PCN- $X$.

\section{PCN-coated separator preparation.}

For the preparation of the PCN-coated separator, a thin slurry containing 80 wt.\% of PCN, 10 wt.\% of Super C65 carbon black and 10 wt.\% of PVDF in Nmethyl-2-pyrrolidone (NMP) was cast onto one side of the pristine polypropylene separator (Celgard 2500) using the doctor blade technique. The coated separator was then vacuum-dried at $50{ }^{\circ} \mathrm{C}$ overnight under a certain mechanical tension to avoid twisting. The dried coated film was cut into discs with a diameter of $14 \mathrm{~mm}$. The areal carbon loading of the coated separators was of $0.20 \mathrm{mg} \mathrm{PCN} \mathrm{cm}^{-2}$.

\section{Physicochemical Characterization.}

Scanning electron microscopy (SEM) images were recorded by using a Quanta FEG650 (FEI) instrument, whereas transmission electron microscopy (TEM) images were obtained on a JEOL (JEM 2100-F) apparatus operating at $200 \mathrm{kV}$. 
Both instruments are equipped with EDX (energy dispersive X-ray spectroscopy) devices. The packing density and electrical conductivity of the carbon powder and composite powders were determined on a homemade apparatus in which the powders are placed between two stainless steel plungers inside a hollow nylon cylinder (inner diameter of $8 \mathrm{~mm}$ ). A pressure of $7.1 \mathrm{MPa}$ was then applied. The $\mathrm{N}_{2}$ sorption isotherms of the carbon and hybrid samples were measured at $-196^{\circ} \mathrm{C}$ using a Micromeritics ASAP 2020 sorptometer. The apparent surface area was calculated by the BET method. The total pore volume was determined from the amount of nitrogen adsorbed at a relative pressure $\left(p / p_{0}\right)$ of 0.95 . The pore size distributions (PSD) were determined by means of the Quench Solid State Density Functional Theory (QSDFT) method for nitrogen. X-ray diffraction (XRD) patterns were obtained on a Siemens D5000 instrument operating at $40 \mathrm{kV}$ and $20 \mathrm{~mA}$, using a $\mathrm{Cu}-\mathrm{K} \alpha$ radiation source. X-ray photoelectron spectroscopy (XPS) was carried out on a Specs spectrometer, operating with $\mathrm{Mg} \mathrm{KR}(1253.6 \mathrm{eV})$ radiation from a double anode at $150 \mathrm{~W}$. The elemental analysis of the samples was carried out on a LECO CHN-932 microanalyzer. The Raman spectra were recorded on a Horiba (LabRam HR-800) spectrometer. The source of radiation was a laser operating at a wavelength of $514 \mathrm{~nm}$ and at a power of $25 \mathrm{~mW}$. The amount of infiltrated sulfur in the S/PCN nanocomposites was determined by thermal treatment up to $600 \stackrel{\circ}{\circ}\left(\mathrm{N}_{2}, 5 \stackrel{\circ}{\circ} / \mathrm{min}\right)$ in nitrogen. For the polysulfide adsorption experiments, a $0.1 \mathrm{M}$ solution of $\mathrm{Li}_{2} \mathrm{~S}_{6}$ was prepared by stirring stoichiometric amounts of $\mathrm{Li}_{2} \mathrm{~S}$ and $S_{8}$ in a mixture of DME/DOL (v/v: 1/1). The mixture was stirred at room temperature overnight until no solid residues were observed. For the calibration, diluted solutions between $1 \mathrm{mM}$ and $10 \mathrm{mM}$ were prepared since the polysulfide 
concentration in real cells generally falls within this range. ${ }^{40}$ For the batch adsorption tests, $10 \mathrm{mg}$ of $\mathrm{PCN}-2.3$ porous carbon nanoparticles were introduced into a closed vial containing $5 \mathrm{ml}$ of a $2 \mathrm{mM}$ solution of polysulfides in DME/DOL (carbon-to-solution ratio of $2 \mathrm{mg} \mathrm{ml}^{-1}$ ). After the addition of the carbon sample, the suspensions were shaken manually and allowed to decant. Aliquots of the solution were extracted after $0.5,1.5$ and $24 \mathrm{~h}$, and the concentration of polysulfides was determined by UV-VIS adsorption.

\section{Electrochemical measurements.}

In a typical preparation procedure, $160 \mathrm{mg}$ of each sulfur/carbon composite, 20 mg of Super C65 carbon black and $20 \mathrm{mg}$ of PVDF binder were mixed together and dispersed in NMP by magnetic stirring to form thick slurries. The slurries were cast onto aluminium foil using the doctor blade technique and then dried at $50{ }^{\circ} \mathrm{C}$ under vacuum overnight. Once dried, the coated foil was cut into discs with a diameter of $10 \mathrm{~mm}$. The areal sulfur loading of the cathodes was around $\sim 2.0 \mathrm{mg} \mathrm{cm}^{-2}$. CR2032 coin-type cells were assembled in an Ar filled glovebox, using a Li metal foil as the anode and a pristine or PCN-coated polypropylene membrane as the separator. $1 \mathrm{M}$ lithium bis(tri-fluoromethane) sulfonimide (LiTFSI) in a mixed solvent of 1,3-dioxolane and 1,2-dimethoxyethane $(\mathrm{DOL} / \mathrm{DEM}, \mathrm{vol} / \mathrm{vol}=1: 1)$ with $1 \mathrm{wt} \% \mathrm{LiNO}_{3}$ was used as the electrolyte. The electrochemical performance of the cells was tested at room temperature in a computer-controlled potentiostat (Biologic VMP3 multichannel generator). Galvanostatic charge/discharge (CD) experiments were carried out over a potential range of $1.7-2.7 \mathrm{~V}\left(\mathrm{vs} . \mathrm{Li}^{+} / \mathrm{Li}\right)$ at different $\mathrm{C}$ rates, ranging from 0.2 to 2C $\left(1 \mathrm{C}=1675 \mathrm{~mA} \mathrm{~g}^{-1} \mathrm{~S}\right)$. Cyclic voltammetry $(\mathrm{CV})$ experiments were performed within the same potential window at a sweep rate of $0.05 \mathrm{mV} \mathrm{s}$. 
Electrochemical impedance spectroscopy (EIS) curves were obtained from fresh cells at open-circuit potential within a frequency range of $100 \mathrm{kHz}$ to $1 \mathrm{mHz}$ at an amplitude of $10 \mathrm{mV}$.

\section{Results and discussion}

\subsection{The synthesis strategy}

The porous carbon nanoparticles (PCN) and the sulfur-carbon nanocomposites (S/PCN) were produced by the chemical activation of polypyrrole-based carbon nanoparticles with sodium thiosulfate in the presence of an inert salt $(\mathrm{KCl})$, according to a procedure recently reported by our group. ${ }^{39,41}$ In the activation process we employed polypyrrole nanoparticles precarbonized at $500^{\circ} \mathrm{C}$, since the direct use of polypyrrole nanoparticles leads to the formation of large aggregates of fused carbon particles (Figure S1). The synthesis procedure is schematically illustrated in Figure 1. At a high activation temperature $\left(800{ }^{\circ} \mathrm{C}\right)$ the reaction between sodium thiosulphate and the precarbonized polypyrrole nanoparticles gives rise to a solid product made up of a mixture of the inert salt $(\mathrm{KCl})$, porous carbon nanoparticles and sodium polysulfides $\left(\mathrm{Na}_{2} \mathrm{~S}_{\mathrm{x}}\right)$. Once this solid has been washed with water, the inorganic substances (i.e. $\mathrm{KCl}, \mathrm{Na}_{2} \mathrm{~S}_{\mathrm{x}}$ ) are completely eliminated, leaving a solid formed exclusively by highly porous carbon nanoparticles (PCN sample). On the other hand, when the solid product is immersed in an acid medium (i.e. $\mathrm{HCl}$ ), polysulfides undergo a disproportionation reaction, leading to the formation of elemental sulfur as follows: ${ }^{42-43}$

$\mathrm{Na}_{2} \mathrm{~S}_{x}+2 \mathrm{HCl} \rightarrow(x-1) \mathrm{S}+\mathrm{H}_{2} \mathrm{~S}+2 \mathrm{NaCl}$ 
Such in situ generated elemental sulfur spontaneously diffuses into the porous network of the PCN due to capillary forces, ${ }^{44}$ giving rise to hybrid sulfur-carbon nanoparticles. This versatile and easy synthesis strategy makes it possible to produce either highly porous carbon nanoparticles (PCN) or sulfur-porous carbon nanocomposites (S-PCN), simply by introducing minor changes into the synthesis methodology (see Figure 1). In this work, both types of materials are used to construct the Li-S batteries. The hybrid sulfur-carbon nanocomposites (S/PCN) are employed as the electroactive material in the cathode whilst the porous carbon nanoparticles (PCN) are coated onto the polypropylene separator to form a shield against the migration of soluble polysulfides.

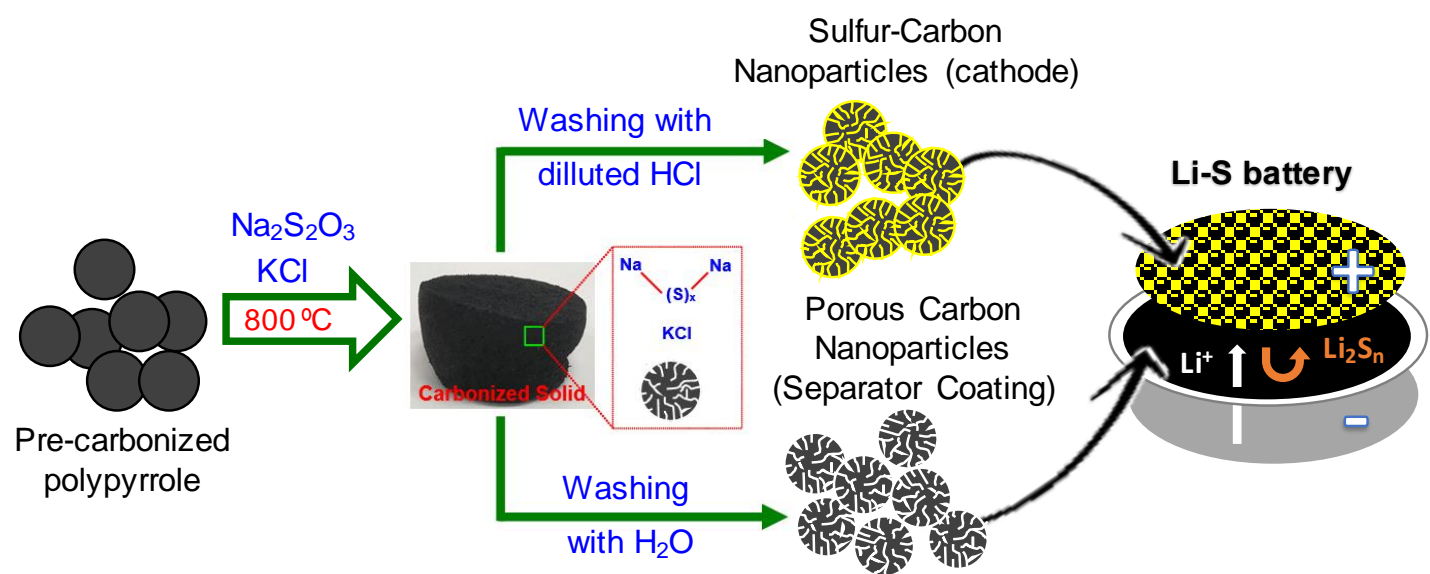

Figure 1. Illustration of the synthesis process for the preparation of porous carbon nanoparticles (PCN) and hybrid sulfur-carbon nanocomposites (S/PCN).

\subsection{Morphology and physicochemical properties of the porous carbon and sulfur-carbon nanoparticles}

An examination of the structure of the porous carbon and sulfur-carbon nanoparticles was carried out by means of scanning electron microscopy (SEM) and transmission electron microscopy (TEM). The synthesized polypyrrole consists of spherical nanoparticles with a size of around 90-130 nm (Figures 
S2a, $b$ and e). When the polymer is carbonized, the resulting carbon nanospheres exhibit a size of around $65-85 \mathrm{~nm}$, which is considerably smaller than that of the polypyrrole (Figures S2c, $d$ and f). It can be appreciated from Figures $\mathrm{S} 3 \mathrm{a}$ and $\mathrm{b}$ that, unlike polypyrrole or carbonized polypyrrole nanoparticles, the activated nanoparticles do not have a perfect spherical morphology. What is more, they exhibit a size of $65 \pm 10 \mathrm{~nm}$, which is smaller than that of the carbonized polypyrrole, (Figure S3c). These results would seem to suggest a certain collapse of the internal structure, attributable to a weakening of the carbon framework as a consequence of the activation process. A PCN sample subjected to TEM inspection shows that the nanoparticles have a highly developed porosity (see Figure S4c). The porosity combines macropores (interparticle voids displayed in Figures S4a and S4b), mesopores (Figure S4d) and micropores corresponding to narrow voids between the disordered graphene-like carbon sheets, as can be seen in Figure S4e. This hierarchical pore organization is confirmed by the nitrogen physisorption experiments, as illustrated in Figure S4f.

Figures $2 \mathrm{a}$ and $2 \mathrm{~b}$ show the SEM microphotographs obtained for the sulfur/carbon nanocomposite S/PCN-2.3 (70.4\%). A comparison with the PCN sample reveals that the S/PCN nanoparticles have a similar microstructural appearance, suggesting that the incorporated sulfur has integrated well inside the pore network. The size of the S/PCN nanocomposites is also similar to that of PCN, as illustrated in Figure 2c. Further examination of the structural characteristics of the S/PCN nanocomposites by TEM reveals an internal structure that is indistinguishable from that of the PCN material. Although none of the infiltrated sulfur is visible in Figures $2 d-f$, the elemental mapping obtained 
by TEM-EDX shows that sulfur has been successfully infiltrated and is homogeneously distributed (Figures $2 \mathrm{~g}-\mathrm{i}$ ). This result is corroborated by the SEM-EDX mapping of the sulfur for the S/PCN-2.2 sample (Figure S5). 

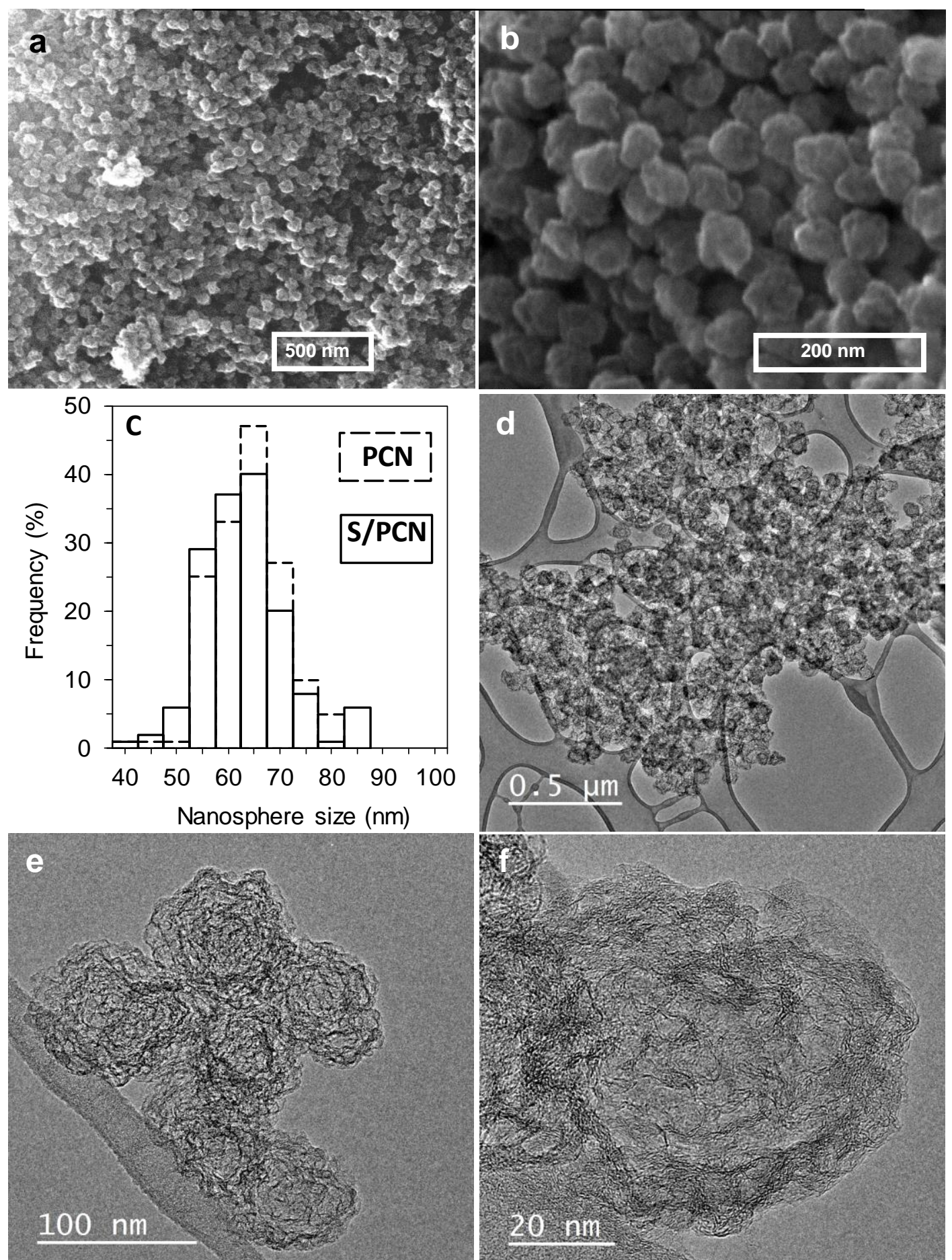

\section{(1)}
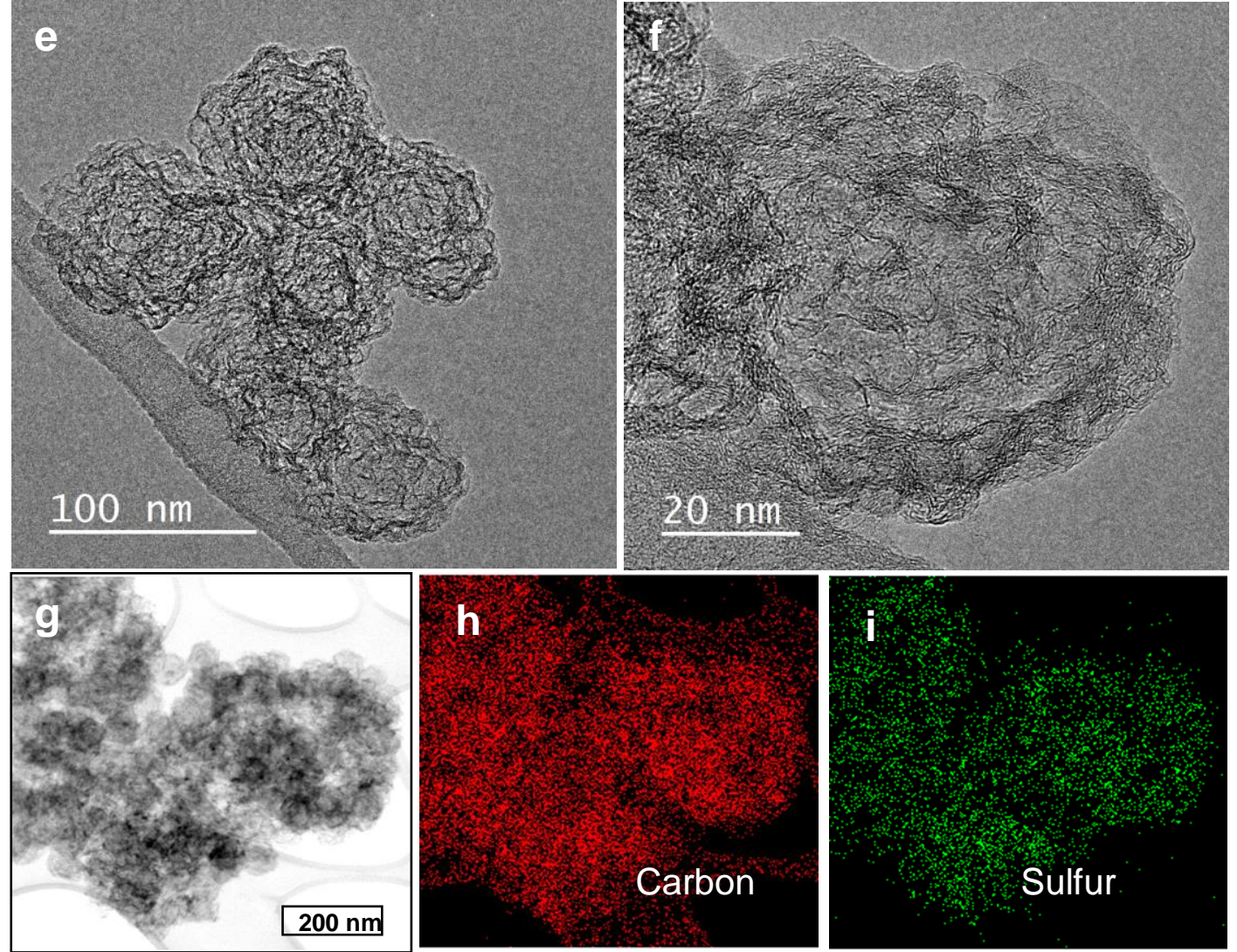

Figure 2. Microstructure of the sulfur-carbon nano-composites: (a, b) SEM images, (c) particle size distributions, (d-f) TEM images and (g-i) TEM-EDX 
elemental mappings of carbon (h) and sulfur (i) collected from the area shown in (g). Sample: S/PCN-2.3.

The textural properties of the PCN and S/PCN samples were investigated by nitrogen physisorption analysis. Figure $3 \mathrm{a}$ and $\mathrm{b}$ display the sorption isotherms and pore size distributions of the PCN samples, whilst the main textural characteristics (i.e., BET surface area, pore volume and micropore volume) for both types of sample are listed in Table 1. The PCN samples have high BET surface areas, in the $1380-1690 \mathrm{~m}^{2} \mathrm{~g}^{-1}$ range, and large pore volumes $\left(1.29-2.20 \mathrm{~cm}^{3} \mathrm{~g}^{-1}\right)$, the micropore volume $(<2 \mathrm{~nm})$ being around $0.40 \mathrm{~cm}^{3} \mathrm{~g}^{-1}$ and $\sim 0.20 \mathrm{~cm}^{3} \mathrm{~g}^{-1}$ in the case of the narrowest micropores $(<1 \mathrm{~nm})$. Inspection of the sorption isotherms of the PCN samples shows that they have a hierarchical porosity made up of micropores, mesopores and macropores (Figure $3 a$ and $\mathrm{S} 4 \mathrm{f}$ ). Hence, the large $\mathrm{N}_{2}$ uptakes for $\mathrm{p} / \mathrm{p}_{\mathrm{o}}>0.95$ can be attributed to the inter-nanoparticle voids (macropores) that are visible in Figures S4a-b. The pore size distributions in Figure $3 b$ reveal that the PCN samples have a framework-confined porosity made up of two pore systems: one constituted by narrow micropores centred at $\sim 0.8 \mathrm{~nm}$ and the other corresponding to micromesopores in the $\sim 1.5-12 \mathrm{~nm}$ range. The incorporation of sulfur leads to a sharp drop in the textural properties in the S/PCN samples, as can be inferred from the sorption isotherms displayed in Figure S6a and from the textural properties shown in Table 1. An analysis of the pore volume values of the S/PCN composites reveals that, for the samples with sulfur contents of up to $70 \%$, a fraction of the pore volume still remains unoccupied (see Table 1 for details). However, for sulfur contents $>80 \%$ the pores are completely filled, as a result of which a certain amount of sulfur is present on the outer surface of the 
carbon nanoparticles. The percentage of sulfur incorporated into the S/PCN nanocomposites can be modulated by simply modifying the amount of $\mathrm{Na}_{2} \mathrm{~S}_{2} \mathrm{O}_{3}$ used in the activation process, as illustrated in Figure S6b. Thus, the percentage of sulfur can be adjusted between $\sim 40 \%$ and $\sim 80 \%$ merely by increasing the $\left(\mathrm{Na}_{2} \mathrm{~S}_{2} \mathrm{O}_{3} / \mathrm{PPy}\right)$ weight ratio from 1.5 to 2.4 . Concurrently with the increase in the amount of infiltrated sulfur, there is a dramatic drop in the carbon yield from $14 \%$ to $3.5 \%$. 
Table 1. Physico-chemical properties of the porous carbon nanoparticles and sulfur/carbon composites.

\begin{tabular}{|c|c|c|c|c|c|c|c|c|c|}
\hline Material & Sample code & $\begin{array}{l}\mathrm{S}_{\mathrm{BET}} \\
\left(\mathrm{m}^{2} \mathrm{~g}^{-1}\right)\end{array}$ & $\begin{array}{l}V_{p} \\
\left(\mathrm{~cm}^{3} \mathrm{~g}^{-1}\right)^{a}\end{array}$ & $\begin{array}{l}V_{\text {micro }}<2 \mathrm{~nm} \\
\left(\mathrm{~cm}^{3} \mathrm{~g}^{-1}\right)^{\mathrm{b}}\end{array}$ & $\begin{array}{l}\text { S }_{\text {infiltrated }} \\
(\text { wt \%) }\end{array}$ & $\begin{array}{l}S_{\text {doped }} \\
(w t \%)\end{array}$ & $\begin{array}{l}\mathrm{N}_{\text {doped }} \\
(\text { wt \%) }\end{array}$ & $\begin{array}{l}\text { Electrical } \\
\text { conductivity } \\
\left(\mathrm{S} \mathrm{cm}^{-1}\right)\end{array}$ & $\begin{array}{l}\text { Packing } \\
\text { density } \\
\left(\mathrm{g} \mathrm{cm}^{-3}\right)\end{array}$ \\
\hline Porous & PCN-1.5 & 1520 & 1.29 & $0.47(0.22)$ & - & 4.18 & 2.69 & 3 & 0.43 \\
\hline \multirow[t]{4}{*}{ carbon } & PCN-2 & 1380 & 1.40 & $0.39(0.20)$ & - & 4.45 & 1.99 & 2.6 & 0.47 \\
\hline & PCN-2.2 & 1690 & 2.07 & $0.43(0.22)$ & - & 5.96 & 1.99 & 2.7 & 0.36 \\
\hline & PCN-2.3 & 1620 & 2.15 & $0.40(0.20)$ & - & 4.41 & 2.38 & 2.5 & 0.34 \\
\hline & PCN-2.4 & 1670 & 2.20 & $0.42(0.19)$ & - & 7.70 & 2.07 & 2.2 & 0.33 \\
\hline \multirow[t]{5}{*}{ S/carbon } & S/PCN-1.5 & - & - & - & 41.7 & - & - & 1.9 & 0.54 \\
\hline & S/PCN-2 & 140 & $0.28(0.37)$ & - & 54.8 & - & - & 1.9 & 0.98 \\
\hline & S/PCN-2.2 & 110 & $0.24(0.51)$ & - & 61.0 & - & - & 1.8 & 1.08 \\
\hline & S/PCN-2.3 & 60 & $0.18(0.30)$ & - & 70.4 & - & - & 0.9 & 1.79 \\
\hline & S/PCN-2.4 & 20 & $0.07(\sim 0)$ & - & 81.9 & - & - & 0.7 & 1.90 \\
\hline
\end{tabular}

${ }^{a}$ The pore volume was calculated for $p / p_{0}=0.95$. The theoretically unoccupied pore volumes deduced by assuming that the sulfur is confined within the porosity of carbon are indicated in brackets. This parameter was calculated by using the formula: $\left[V_{p} \times\left(1-a_{s}\right)-a_{s} / 2.07\right]$, where $a_{s}$ is the fraction of sulfur and 2.07 its density; ${ }^{b}$ The volume of micropores smaller than $1 \mathrm{~nm}$ are given in brackets, ${ }^{\mathrm{c}} \mathrm{S}$ determined by thermal treatment up to $600{ }^{\circ} \mathrm{C}\left(\mathrm{N}_{2}\right),{ }^{\mathrm{d}}$ percentages of nitrogen and sulfur determined after the infiltrated sulfur has been removed by thermal treatment up to $600^{\circ} \mathrm{C}\left(\mathrm{N}_{2}\right)$. 

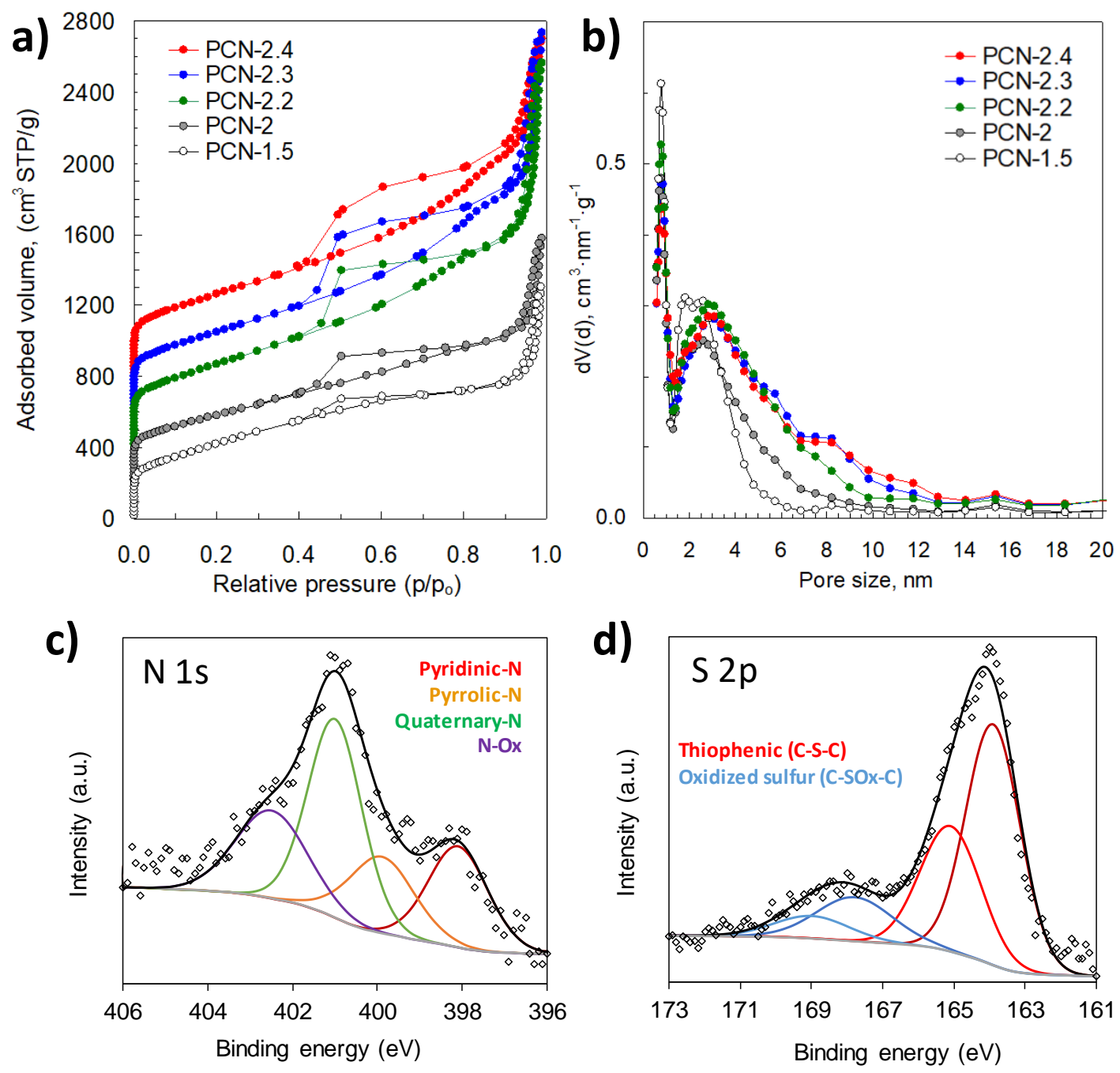

Figure 3. (a) Nitrogen sorption isotherms and (b) pore size distributions of the porous carbon nanoparticles. High-resolution XPS spectra of (c) N 1s and (d) $S$ $2 \mathrm{p}$, collected from the PCN-1.5 sample. In Figure (a), the isotherms of PCN-2, PCN-2.2, PCN-2.3 and PCN-2.4 are shifted up by 200, 400, 600 and $800 \mathrm{~cm}^{3} \mathrm{~g}^{-}$ ${ }^{1}$ respectively for the sake of clarity.

The microstructure of the S/PCN samples was analysed by X-ray diffraction and Raman spectroscopy. The XRD patterns in Figure S7a reveal that the composites with a S content of up to around $70 \%$ do not exhibit any 
sharp crystalline peak, but only a broad band at $2 \theta \sim 15-30^{\circ}$, which is typical of carbons with a disordered structure. These results suggest that the infiltrated sulfur has integrated well within the pores of PCN as an amorphous $\mathrm{S}_{8}$ phase. In contrast, the S/PCN-2.4 sample (with a sulfur content of $80 \%$ ) exhibits peaks that are characteristic of orthorhombic sulfur, indicating that a fraction of the sulfur is located outside of the pores in the form of a crystalline phase. This interpretation is confirmed by the Raman spectra in Figure S7b. Thus, whereas the composites with $<70 \%$ of sulfur only exhibit two broad bands at $\sim 1350 \mathrm{~cm}^{-1}$ ( $\mathrm{D}$ band) and $\sim 1600 \mathrm{~cm}^{-1}$ ( $\mathrm{G}$ band) which are typical of carbon materials with a disordered structure, the spectrum of S/PCN-2.4 contains another three peaks at $154 \mathrm{~cm}^{-1}, 219 \mathrm{~cm}^{-1}$ and $473 \mathrm{~cm}^{-1}$ associated with S-S vibrational modes typical of crystalline sulfur. ${ }^{45}$ These results show that for the S/PCN samples with sulfur contents lower than $\sim 80 \%$, all of the sulfur is located inside the pore structure of the carbon host as an amorphous phase, which is in agreement with the data derived from the textural analysis.

The porous carbons used to accommodate the sulfur must have a good conductivity to allow the unimpeded transfer of electrons. The PCN samples satisfy this requirement, as can be inferred from the electrical conductivities of the pressed carbon samples that are in the 2.2-3 $\mathrm{S} \mathrm{cm}^{-1}$ range (Table 1). Importantly, in the case of the S/PCN composites, the electrical conductivities are also high (0.7-1.9 $\left.\mathrm{S} \mathrm{cm}^{-1}\right)$; even the sample with $82 \% \mathrm{~S}$ exhibits a conductivity of $0.7 \mathrm{~S} \mathrm{~cm}^{-1}$ (see Table 1). These results show that the electrical contact between the S/C particles is preserved, which in turn indicates that the sulfur is predominantly concentrated inside the pores of the PCN nanoparticles. Because of their high pore development, the PCN nanoparticles have relatively 
low packing densities in the $0.33-0.47 \mathrm{~g} \mathrm{~cm}^{-3}$ range (Table 1). However, as the sulfur occupies more and more pores, the packing density rapidly rises to values close to the density of sulfur $\left(2.07 \mathrm{~g} \mathrm{~cm}^{-3}\right)$, as in the case of the fully infiltrated samples such as S/PCN-2.4 (82\% S, packing density: $\left.1.90 \mathrm{~g} \mathrm{~cm}^{-3}\right)$. This is an important point given that the higher the packing density, the smaller the amount of electrolyte needed to soak the battery.

An important feature of the porous carbons produced by our synthesis strategy is that they are co-doped with significant amounts of nitrogen (2-2.7 wt.\%) and sulfur (4.18-7.7 wt.\%) heteroatoms, as indicated in Table 1. These N and $\mathrm{S}$ groups have different origins. Whereas the nitrogen functionalities derive from the N-rich precursor (polypyrrole), the sulfur functional groups are generated during the activation process as a consequence of the hightemperature reactions between the carbonaceous matter and the oxidizing agent (sodium sulfate). The combination of both heteroatoms plays an important role in the electrochemical performance of the composites in a Li-S battery. Several authors have presented evidence to show that the dual doping of porous carbon hosts with $\mathrm{N}$ and $\mathrm{S}$ heteroatoms significantly increases the interaction with polysulfide species, which may help to suppress the shuttle phenomenon. ${ }^{35-36,46-47}$ In particular, Zhou et al. demonstrated, by means of DFT calculations, that N/S co-doping has a synergistic effect that provides stronger binding energies for anchoring polysulfides than mono-doped ( $\mathrm{S}$ or $\mathrm{N}$ ) carbons. ${ }^{47}$ The EDX mappings of sulfur and nitrogen in the PCN samples obtained by means of TEM (Figure S8) and SEM (Figure S9) analyses prove that these heteroatoms are uniformly distributed over the carbon particles. The nature of the $\mathrm{N}$ and $\mathrm{S}$ groups was determined by $\mathrm{X}$-ray photoelectron 
spectroscopy (XPS). The XPS survey spectra obtained for the porous carbons only contain four peaks associated to $C 1 s, O 1 s, N 1 s$ and $S 2 p$, which rules out the presence of foreign elements (Figure S10a). The results of the deconvolution of the high-resolution $C 1 s, N$ 1s and S 2p XPS spectra corresponding to the PCN-1.5 sample are shown in Figures S10b, 3c and 3d, respectively. In the $\mathrm{C}$ 1s XPS spectrum, besides the peaks at $284.5 \mathrm{eV}, 286.5$ $\mathrm{eV}, 287.8 \mathrm{eV}$ and $289.1 \mathrm{eV}$ associated to $\mathrm{C}=\mathrm{C}, \mathrm{C}-\mathrm{O}, \mathrm{C}=\mathrm{O}$ and $\mathrm{O}-\mathrm{C}=\mathrm{O}$ bonds, there is an additional peak at $285.4 \mathrm{eV}$ that can be ascribed to carbon covalently attached to $\mathrm{S}$ or $\mathrm{N}$ atoms. ${ }^{47}$ Regarding the $\mathrm{N}$ species, the peaks identified in the $\mathrm{N}$ 1s spectrum indicate the presence of pyridinic- $\mathrm{N}(398.2 \mathrm{eV})$, pyrrolic/pyridonic- $\mathrm{N}(400.1 \mathrm{eV})$, quaternary- $\mathrm{N}(400.9 \mathrm{eV})$ and oxidized nitrogen groups $(402.6 \mathrm{eV})$. The $\mathrm{S} 2 \mathrm{p}$ spectrum exhibits two doublets, one at 164.1 and $165.3 \mathrm{eV}$, that is ascribed to thiophenic moieties (C-S-C), and another at 168.0 and $169.2 \mathrm{eV}$, that can be assigned to oxidized sulfur functionalities (C-SO $\left.{ }_{x}-\mathrm{C}\right)$.

\subsection{Structure and polysulfide trapping ability of the PCN-coated separator}

The PCN-coated separator was fabricated by coating a PCN-based slurry $(80 \%$ PCN, $10 \%$ binder and $10 \%$ carbon black) onto one side of the pristine polypropylene separator using the doctor blade technique. As can be seen in Figure 4a, the thin layer of PCN is well-adhered to the pristine PP separator and it can be hardly flexed or twisted maintaining intact its mechanical integrity. The morphology of the PCN coating layer was investigated by SEM. The top view micrograph of the coating surface shows the absence of cracks or wrinkles (Figure $4 b$ ). Indeed, the thickness of the coating is very homogeneous and the PCN particles are densely packed. A compact PCN layer devoid of preferential 
diffusion pathways is essential for an efficient trapping of lithium polysulfides. As can be seen in Figure 4c, the thickness of the carbon coating is as low as 10$15 \mu \mathrm{m}$. Remarkably, the mass loading of this coating is of only $0.25 \mathrm{mg} \mathrm{cm}^{-2}$ $\left(0.20 \mathrm{mg} \mathrm{cm}^{-2}\right.$ of $\left.\mathrm{PCN}\right)$. It is important to note that a thin but effective porous coating is of special importance since high loads of coating would significantly increase the weight and thickness of the separator, as well as the amount of electrolyte required to soak the battery. The nanometric size of the PCN particles allows the effective and easy coating of the PP separator by means of a simple procedure that can be easily implemented in large scale production processes. Moreover, the PCN layer has a high surface conductivity of $3.95 \mathrm{~S}$ $\mathrm{cm}^{-1}$, as determined by the Van der Pauw equation using the four-point probe technique. A good electric conductivity is a key characteristic for the carboncoated separator since it can then act not only as a polysulfide barrier, but also as a peripheral current collector, boosting the redox accessibility of the sulfur species. 

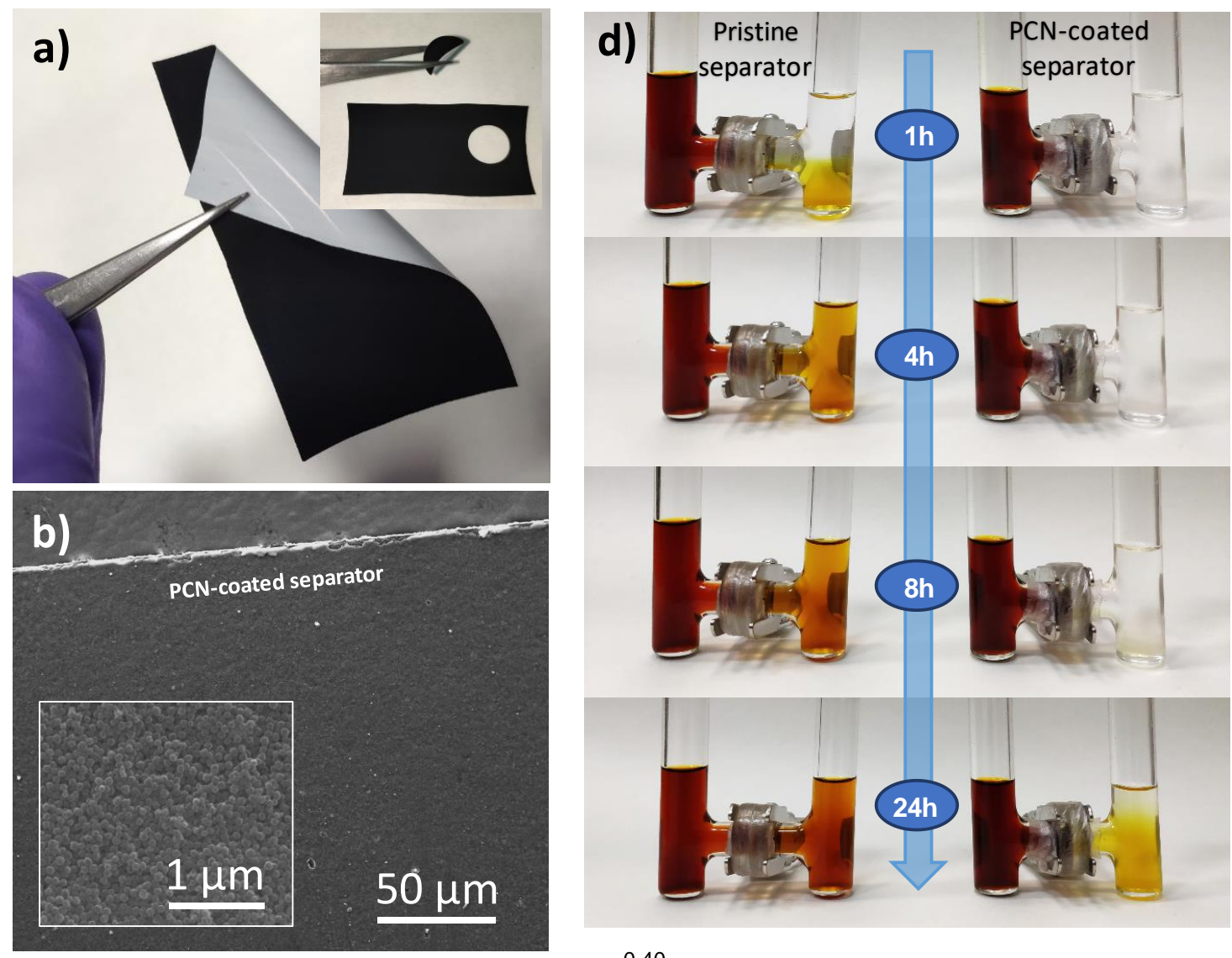

e)
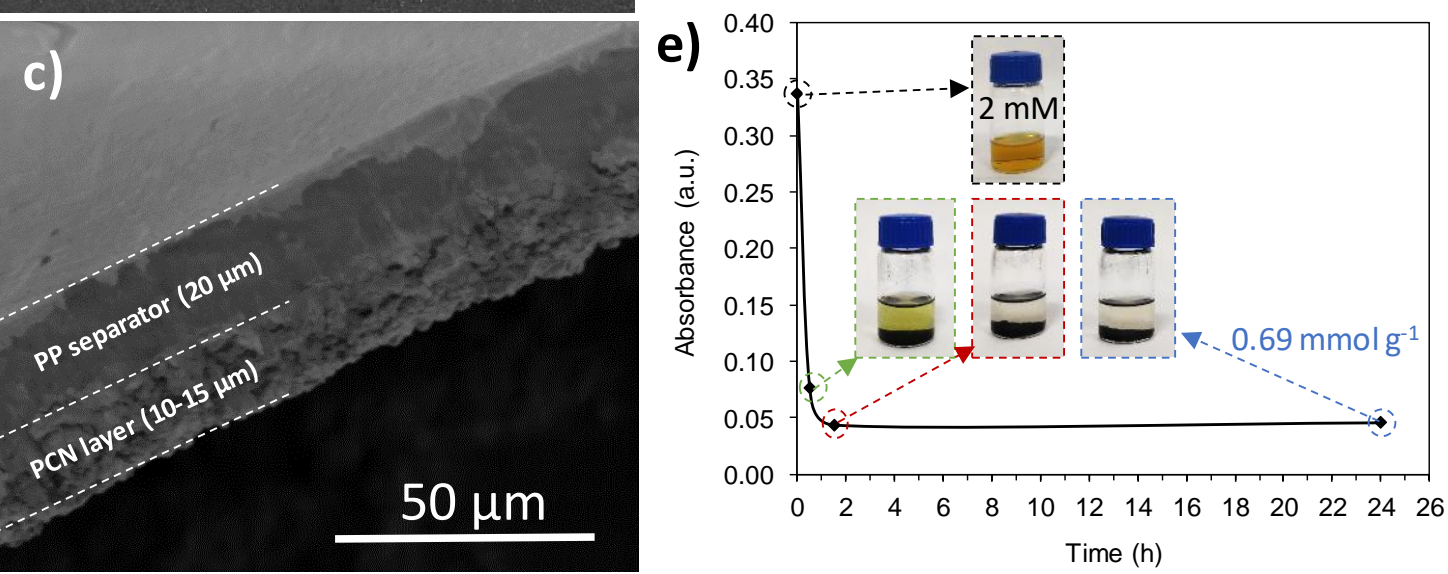

Figure 4. (a) Digital pictures of the PCN-coated PP separator showing the strong adhesion and mechanical stability of the coating layer. (b) Top and (c) cross-sectional SEM images of the PCN-coated separator. (d) Images of the $\mathrm{H}$ shaped glass cells containing the polysulfide solution (left half-cell) and the DME/DOL mixture (right half-cell) connected by the pristine or PCN-modified separator. (e) Values of absorbance at $400 \mathrm{~nm}$ versus time for a $2 \mathrm{mM} \mathrm{Li}_{2} \mathrm{~S}_{6}$ solution containing the PCN-2.3 porous carbon, and the corresponding digital pictures of the batch experiment. 
The polysulfide trapping capacity of the PCN-coated separator was determined using an $\mathrm{H}$-shaped glass cell. As shown in Figure $4 \mathrm{~d}$, the half-cell on the left was filled with a $50 \mathrm{mM}$ solution of polysulfides $\left(\mathrm{Li}_{2} \mathrm{~S}_{6}\right)$ in $\mathrm{DME} / \mathrm{DOL}$, and the right half-cell was filled with the DME/DOL mixture. The two half-cells were separated by a disc cut out of the pristine PP separator (Figure 4d, left) or by the PCN-coated separator (Figure $4 \mathrm{~d}$, right). In the case of the pristine separator, the polysulfides rapidly diffuse towards the right half-cell, and quickly colour the DME/DOL mixture. However, with the PCN coating layer, the migration of polysulfides is impeded by virtue of the physical barrier effect and the polysulfide adsorption capacity of the porous nanoparticles. The capacity to adsorb polysulfides was further analyzed by means of a batch adsorption test. $10 \mathrm{mg}$ of the PCN-2.3 porous carbon nanoparticles was added to a closed vial containing $5 \mathrm{~mL}$ of a $2 \mathrm{mM}$ solution of polysulfides in DME/DOL. The adsorption capacity of the PCN was monitored by measuring the change in colour of the solution in contact with the porous sorbent. As shown in Figure 4e, the absorbance of the solution at $400 \mathrm{~nm}$ decreases sharply after only $30 \mathrm{~min}$ of contact without stirring, and reaches equilibrium after $1.5 \mathrm{~h}$. The adsorption capacity of the PCN at this time is $0.69 \mathrm{mmol} \mathrm{g}^{-1}$, and $0.62 \mathrm{mmol} \mathrm{g}^{-1}$ after only $0.5 \mathrm{~h}$, as calculated by applying a mass balance to the adsorption results (see experimental section and Figure $\mathrm{S} 11$ for calibration details). On the basis of the porous structure of PCN-2.3, its maximum adsorption capacity concurs well with that calculated using the model proposed by Hippauf et al. for hydrophobic carbons, which assigns different polysulfide adsorption capacities for each type of pore (the theoretical adsorption capacity according to this model is $0.71 \mathrm{mmol}$ 
$\left.\mathrm{g}^{-1}\right){ }^{48}$ The high content in narrow micropores and surface $\mathrm{N}$ and $\mathrm{S}$ functionalities is the main factor responsible for the adsorption of LiPS (the micropores adsorb up to eight times more polysulfides than the mesopores), ${ }^{48-49}$ while the mesopores provide convenient diffusion channels that are responsible for the fast trapping ability of the PCN coating, ${ }^{48}$ as can be deduced from the short equilibration time in the batch adsorption test.

\subsection{Electrochemical performance of Li-S cells with a PCN-coated separator}

As depicted in Figure 1, the S/PCN composites and the PCN nanoparticles were employed as the cathode active material and as the separator coating layer, respectively, in the Li-S batteries. The S/PCN-2.3 sample was selected for the formulation of the cathode because it combines a high sulfur content (70.4 wt\%) with a good carbon yield (7\%) (see Figure S6b). Figure S12a shows the cyclic voltammograms corresponding to the S/PCN-2.3 cathode during the $1^{\text {st }}, 5^{\text {th }}$ and $10^{\text {th }}$ charge-discharge cycles. The cathodic sweep reveals two peaks associated to the multi-step reduction of sulfur. Thus, at a cell voltage of $2.28 \mathrm{~V}$ the elemental sulfur is reduced to soluble long-chain lithium polysulfides $\left(\mathrm{Li}_{2} \mathrm{~S}_{\mathrm{X}}\right.$, $4 \leq x \leq 8)$, while the peak recorded at $2.05 \mathrm{~V}$ evidences the conversion of polysulfides to the solid discharge products $\mathrm{Li}_{2} \mathrm{~S}_{2}$ and $\mathrm{Li}_{2} \mathrm{~S}$. Analogously, the anodic sweep describes two overlapping signals centred at 2.33 and $2.38 \mathrm{~V}$ associated with the reversible oxidation of $\mathrm{Li}_{2} \mathrm{~S}$ and $\mathrm{Li}_{2} \mathrm{~S}_{2}$ to $\mathrm{S}_{8}{ }^{50}$ As can be seen from the overlapping plots, there is little change in the redox peaks during the first charge-discharge cycles, which confirms the good reversibility of the process. The micro-mesoporous structure of PCN-2.3 seems to be the key to 
this cycling stability, as it is able to accommodate well the volume changes taking place during the charge and discharge processes. The carbon scaffold does not contribute to lithium storage within the potential range studied, as deduced from the flat cyclic voltammogram of the battery using the PCN-2.3 cathode (without sulfur) shown in Figure S12b.

Batteries were assembled using the pristine and PCN-coated PP separators facing the S/PCN cathode. The PCN-2.3 sample (the carbon host for the S/PCN-2.3 composite employed as the cathode) was used for the separator coating layer. Due to the conductive nature of the thin PCN coating, the use of the modified separator reduced the internal resistance of the cell. This was revealed by electrochemical impedance spectroscopy experiments carried out on fresh batteries. Figure $5 a$ shows the Nyquist plots of batteries with the pristine and the modified separators. Both plots display a semicircle in the high frequency region ascribable to the charge transfer resistance $\left(R_{C T}\right)$, as well as a sloped line at low frequencies associated to mass transfer restrictions $\left(R_{M T}\right)$. The $R_{C T}$ values, given by the amplitude of the semicircle, are around $95 \Omega$ and $69 \Omega$ in the cells built with the pristine and modified separators, respectively, which represents a reduction of $\sim 30 \%$ in cell resistance with the application of a thin PCN coating. The PCN layer is in contact with the outer surface of the cathode, where the electroactive sulfur is less accessible by electronic conduction. This coating acts as a supplementary current collector and facilitates charge transportation throughout the whole cathode. ${ }^{31}$ The cyclic voltammograms of the battery with the S/PCN-2.3 cathode and the PCN-2.3 coating layer at different scan rates are shown in Figure S13a. The redox signals were well retained as the scan rate increased. Moreover, following the 
Randles-Sevcik equation, the intensity of the anodic peak bears a linear relationship with the square root of the scan rate (Figure S13b), which suggests that the electrochemical process is diffusion-limited.

a)

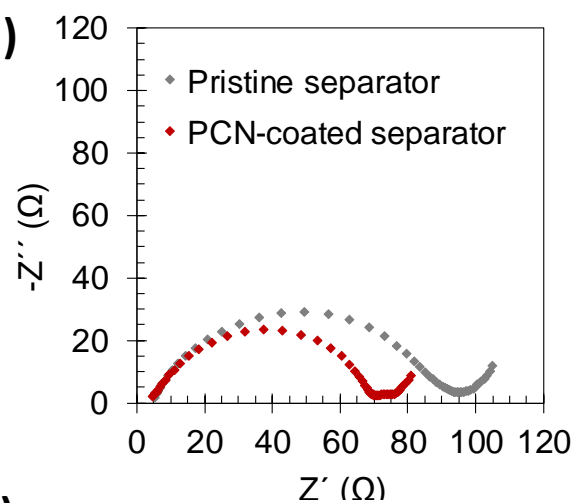

c)

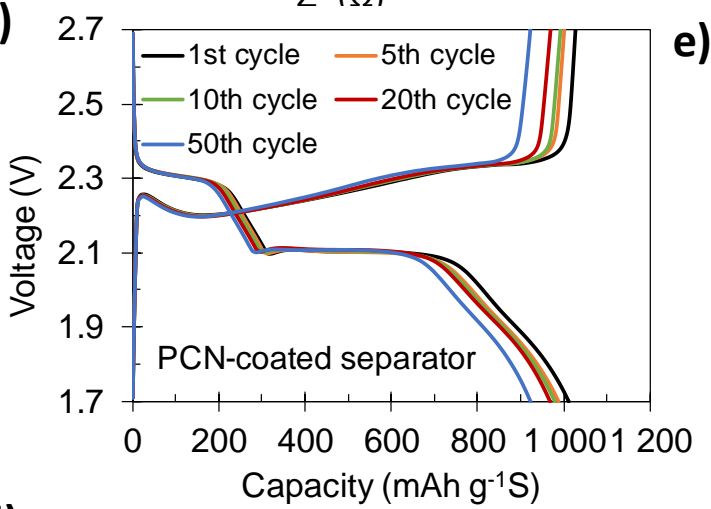

b)

e)
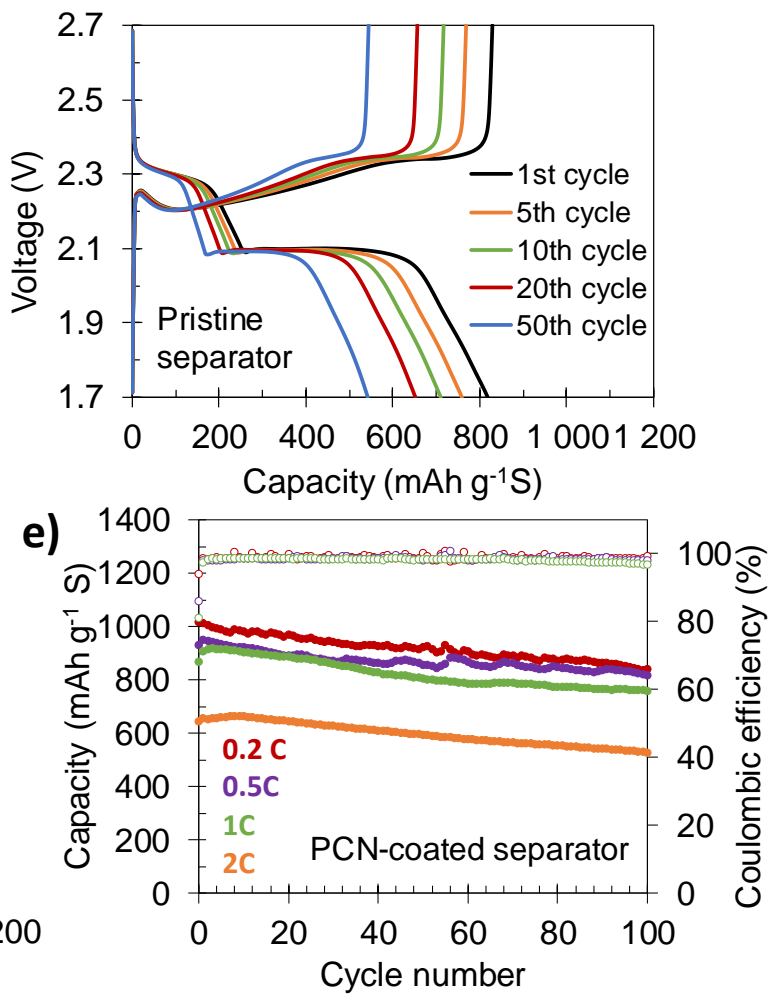

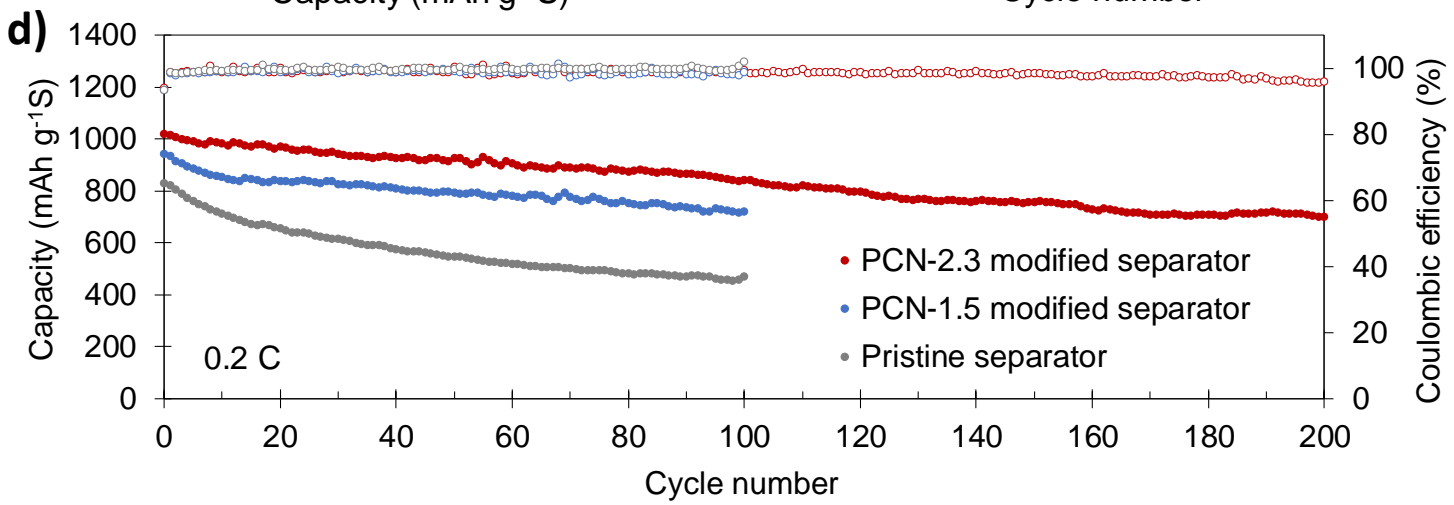

Figure 5. (a) Nyquist plots of the batteries with the pristine and CPN-coated separator; (b) galvanostatic charge-discharge curves of the S/ PCN-2.3 batteries with the pristine separator and (c) with the coated separator at different cycling stages (current density: 0.2C); (d) cycling stability of the batteries with the pristine and modified separators; (e) cycling performance of 
the batteries with the PCN-2.3-modified separator at different charge-discharge rates. The sulfur load in the cathodes is $2 \mathrm{mg} \mathrm{s} \mathrm{cm}^{-2}$.

Figures $5 b$ and $5 c$ show the galvanostatic charge-discharge profiles of the batteries with the pristine separator and PCN-modified separator, respectively, run at a current density of $0.2 \mathrm{C}$. The profiles display two discharge plateaus associated with the sulfur reduction reactions, as well as two continuous charge plateaus related to the charge processes observed by cyclic voltammetry. The cell with the pristine PP separator experiences a significant decrease in the length of both discharge plateaus with cycling. The length of the upper plateau reflects the amount of polysulfides generated and the ability of both the carbon coating and the carbon scaffold in the cathode to retain polysulfides. As can be observed, this plateau gets notably shorter with cycling in the cell with the pristine separator. In contrast, the battery with the PCN-modified separator displays longer discharge plateaus that show little variation upon cycling. The initial capacity of the upper plateau $\left(Q_{H}\right)$ is $318 \mathrm{mAh} \mathrm{g}^{-1}$ for the battery with the modified separator, and after 100 charge-discharge cycles $84 \%$ of this capacity is retained (see Figure S14). On the other hand, the high voltage plateau recorded for the battery with the pristine separator gets shorter much more quickly, and only $55 \%$ of its capacity is retained in the $100^{\text {th }}$ cycle. These results evidence that the PCN coating on the separator acts as a highly effective trap for polysulfides, favouring the reuse of sulfur/Li $2 \mathrm{~S}$ and helping to sustain the reversibility of the charge-discharge process.

The cycling performance of the batteries with pristine and PCN-coated separators at a current rate of $0.2 \mathrm{C}$ is summarized in Figure $5 \mathrm{~d}$. Here it can be 
seen that the capacity of the cell with the PCN-coated separator is fully retained from the very first cycles. This behaviour contrasts with the rapid decay in capacity observed in other reported Li-S systems, even when modified separators or self-standing barriers are used. ${ }^{31,51-52}$ The battery with the PCN2.3 coated separator exhibits an initial discharge capacity of $1020 \mathrm{mAh} \mathrm{g}^{-1}$, and retains $841 \mathrm{mAh} \mathrm{g}^{-1}$ after 100 charge-discharge cycles with a coulombic efficiency above 99.3\%. After 200 cycles, the battery still capable of delivering $711 \mathrm{mAh} \mathrm{g}^{-1}$. The capacity and cycling stability of this battery compares favourably with other reported battery systems with porous carbon interlayers ${ }^{53}$ or graphene oxide- or CNT-coated separators. ${ }^{23}$ The battery with the nonmodified separator achieves a lower capacity of $828 \mathrm{mAh} \mathrm{g}^{-1}$ in the first cycle, and experiences a worse capacity retention (only $466 \mathrm{mAh} \mathrm{g}^{-1}$ at the $100^{\text {th }}$ cycle). The significant increase in sulfur utilization with the introduction of a conductive membrane/coating layer between the cathode and the separator has also been mentioned in previous reports. ${ }^{31,54-56}$ The effect of the thin carbon coating on the self-discharge of the batteries was also assessed. Thus, the batteries were charged and discharged at $0.2 \mathrm{C}$. During the $10^{\text {th }}$ cycle, the discharge was stopped at $2.15 \mathrm{~V}$ and the batteries were allowed to rest for 3 days. As shown in Figure S15, the PCN coating layer is able to suppress the self-discharge phenomenon, diminishing the capacity drop experienced between the $10^{\text {th }}$ and $9^{\text {th }}$ cycles by $\sim 50 \%$. In this work we also explored the use of PCN-1.5 as a coating material for the separator. The porous nanoparticles in PCN-1.5 are richer in micropores $\left(0.47 \mathrm{~cm}^{3} \mathrm{~g}^{-1}\right)$ than in PCN-2.3 $\left(0.40 \mathrm{~cm}^{3} \mathrm{~g}^{-1}\right)$, while the latter has a notably higher pore volume (2.15 vs. $1.29 \mathrm{~cm}^{3} \mathrm{~g}^{-1}$ ) including numerous mesopores larger than $4 \mathrm{~nm}$ (see PSD in Figure 3b). As 
can be seen in Figure $5 d$, both the capacity and the cycling performance of the cell with the PCN-1.5 coating also exceed those of the battery with the unmodified separator. However, the highly porous network of PCN-2.3, which is rich in both micro- and mesopores, seems more beneficial. The superior electrochemical performance of the battery with the PCN-2.3-coated separator is attributed to two main factors. First, the conductive nature of the thin PCN coating allows electronic access to a larger fraction of the sulfur in the cathode, making it possible to achieve an initial capacity $23 \%$ higher than that of the battery with the pristine separator. Secondly, as demonstrated in the polysulfide adsorption experiments, the porous structure of the compact PCN coating acts as a perfect trap for polysulfides, thereby preventing their migration to the anode side. At the same time, its micro-mesoporous network allows the accommodation and reutilization of the sulfur compounds, thus minimizing the loss of active material and providing the redox processes with a good reversibility. Comparable or higher values of capacity have been achieved by using barriers made up of nanocarbons (graphene, carbon nanotubes) ${ }^{28,} 55$ and/or metal oxides ${ }^{54}$ or carbon coatings prepared by sophisticated fabrication procedures (e.g. using hard templates or multistep coatings). ${ }^{31-32,57-58}$ However, the adoption of simple procedures with straightforward synthesis and processing stages such as the one proposed in this study, offers more promise from the point of view of applicability. The cycling performances of the batteries with the NPC-2.3 coating were studied at higher current rates of $0.5 \mathrm{C}, 1 \mathrm{C}$ and 2C. As shown in Figures 5e and S16, the capacity delivered by the batteries is well retained up to a current rate of $1 \mathrm{C}$. It is important to note that, at this discharge rate, the battery is able to achieve a maximum discharge capacity of 
$916 \mathrm{mAh} \mathrm{g}^{-1}$, and as much as $757 \mathrm{mAh} \mathrm{g}^{-1}$ in the $100^{\text {th }}$ cycle. At a high current rate of $2 \mathrm{C}$, the cell displays an initial capacity of $645 \mathrm{mAh} \mathrm{g}^{-1}$, and is capable of running for 500 cycles with a capacity fade of only $0.089 \%$ per cycle (see Figure S17).

It should also be pointed out that the thickness of the separator coating layer is thin enough not to constitute an important volume/mass fraction in the overall cell configuration. This is of special importance since the energy density of the cell decreases with an increase in the coating layer thickness. ${ }^{54}$ The structural and chemical characteristics of the PCN-2.3 porous carbon allow a good performance of the coating layer even with such a low thickness (only 10-15 $\mu \mathrm{m})$. Other porous carbons used as polysulfide barriers usually need to be employed with much higher thicknesses or mass loadings to achieve a good performance or to build stable self-standing films. ${ }^{31,51,56,59}$ In our batteries, the mass loading of the PCN coating accounts only for $6.6 \%$ of the mass of both the cathode and the PCN layer, which translates into a decrease in the sulfur fraction of only 3.7 wt.\% if the two PCN-based components (the composite cathode and the PCN coating) are taken into account. This contrasts with notable decreases of as much as $30 \%$ in the sulfur fraction reported for other modified separators. ${ }^{31}$ The mass fraction of the coating layer is significantly reduced when the batteries have cathodes with a higher areal loading. For example, we explored the use of S/PCN-2.3 cathodes with a sulfur loading above $6 \mathrm{mg} \mathrm{cm}^{-2}$. These cathodes have a thickness of ca. $150 \mu \mathrm{m}$ and a packing density of $1.01 \mathrm{~g} \mathrm{~cm}^{-3}$. In this case, the mass of the PCN-2.3 layer accounted for only $2.3 \%$ of the mass of the cathode plus carbon coating, which represents a reduction in sulfur content of only $1.3 \%$. It is well known that the 
performance of highly loaded cathodes is adversely affected by a poor electrical contact, and also that their integrity is severely damaged upon cycling. ${ }^{60}$ However, the high loading S/PCN-2.3 cathode coupled with a PCN-modified separator displayed a good performance. Figures $6 a$ and $6 b$ show the galvanostatic charge-discharge profiles and the cycling stability of this battery, expressed in terms of areal capacity. As a consequence of its high sulfur loading, when it was first cycled at $0.1 \mathrm{C}\left(1.04 \mathrm{~mA} \mathrm{~cm}^{-2}\right)$, the battery displayed an areal capacity as high as $6.4 \mathrm{~mA} \mathrm{~h} \mathrm{~cm}^{-2}\left(1025 \mathrm{~mA} \mathrm{~h} \mathrm{~g}^{-1}\right.$, see Figure S18). Furthermore, despite its high sulfur content and areal loading, the chargedischarge processes in this battery functioned to a high degree of efficiency, above $94 \%$, which evidences the absence of polysulfides shuttling. After a couple of cycles at $0.1 \mathrm{C}$, the current density was doubled $\left(2.08 \mathrm{~mA} \mathrm{~cm}{ }^{-2}\right)$, reaching a capacity of $4.5 \mathrm{~mA} \mathrm{~h} \mathrm{~cm}{ }^{-2}$ that was retained throughout the cycling. Moreover, the battery was still able to provide $2.7 \mathrm{~mA} \mathrm{~h} \mathrm{~cm}{ }^{-2}$ even after 100 charge-discharge cycles.
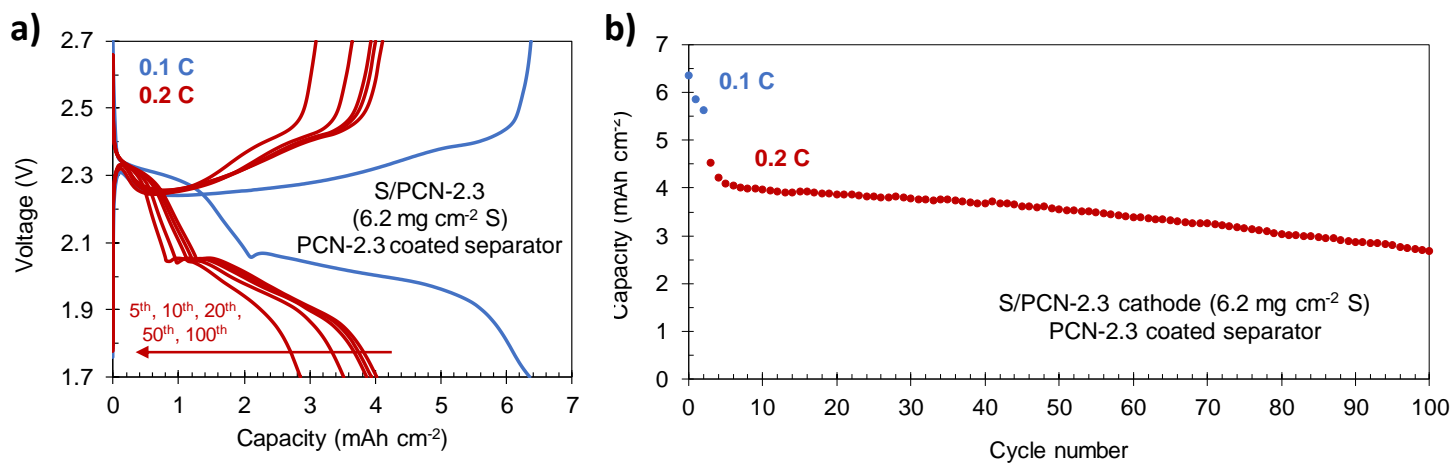

Figure 6. Evolution of the areal capacity of the battery with the S/PCN-2.3 cathode and the PCN-2.3-coated separator, using a sulfur loading of $6.2 \mathrm{mg} \mathrm{S} \mathrm{cm}^{-2}$. (a) Representative galvanostatic plots and (b) cycling performance. 


\section{Conclusions}

A new straightforward synthesis strategy for the production of porous carbon nanoparticles and sulfur/porous carbon composites is presented. The synthesis procedure relies on the use of polypyrrole nanoparticles as the carbon source and sodium thiosulfate as the porogenic agent and sulfur source. By introducing minor changes, this methodology allows the production of high surface area $\mathrm{N}$ S-codoped carbon nanoparticles or sulfur-carbon composites made up of porous carbon nanoparticles filled with in situ infiltrated sulfur. The porous carbon nanoparticles possess a unique structure, combining a uniform particle size $\left(\sim 65 \mathrm{~nm}\right.$ ) with a high specific surface area (up to $\left.1690 \mathrm{~m}^{2} \mathrm{~g}^{-1}\right)$, a high pore volume (up to $2.20 \mathrm{~cm}^{3} \mathrm{~g}^{-1}$ ), a considerable amount of $\mathrm{N}$ and $\mathrm{S}$ heteroatom doping (up to 7.7 wt.\% S and $2.1 \mathrm{wt} . \% \mathrm{~N}$ ) and a high electronic conductivity (2.2-3.0 S cm$\left.~^{-1}\right)$. The in situ synthesized S/C composites were employed as cathodes in Li-S cells, while the porous carbon nanoparticles were used as a polysulfide barrier coating the separator. The nanosized porous carbon particles deposited on the separator gave rise to a thin yet effective barrier that improved the sulfur utilization and the cycling stability of the battery with only a negligible reduction in the sulfur content of the cell. The battery achieved $1020 \mathrm{~mA} \mathrm{~h} \mathrm{~g}^{-1} \mathrm{~S}$ at a discharge current density of $0.2 \mathrm{C}$, and $645 \mathrm{~mA} \mathrm{~h} \mathrm{~g}^{-1} \mathrm{~S}$ with a tenfold increase in current, and these capacities were maintained from the very first cycles (capacity decay of $0.089 \%$ per cycle over 500 cycles). The applicability of these materials was further verified by the analysis of a battery with a $S$ mass loading $>6 \mathrm{mg} \mathrm{cm}^{-2}$. The results confirm the suitability of our proposed versatile synthesis method for the unsophisticated preparation of carbon and 
sulfur/carbon nanoparticles intended for implementation in different components of Li-S batteries.

\section{Acknowledgments}

This research work was supported by projects RTI2018-093712-B-I00

(MCIU/AEI/FEDER, UE) and IDI/2018/000148 (regional GRUPIN2018).

\section{Conflict of Interest}

The authors declare no conflict of interest.

\section{Supporting Information}

SEM and TEM images, SEM-EDX and TEM-EDX elemental mappings, Particle size distributions, $\mathrm{N}_{2}$ adsorption isotherms, XRD patterns, Raman spectra, XPS general and high resolution C1s spectra, UV-Vis spectra and calibration line, cyclic voltammetries and galvanostatic charge-discharge results.

\section{References}

1. Choi, J. W.; Aurbach, D., Promise and reality of post-lithium-ion batteries with high energy densities. Nature Reviews Materials 2016, 1 (4), 16013.

2. Ould Ely, T.; Kamzabek, D.; Chakraborty, D.; Doherty, M. F., Lithium-sulfur batteries: state of the art and future directions. ACS Applied Energy Materials 2018, 1 (5), 1783-1814.

3. Ren, W.; Ma, W.; Zhang, S.; Tang, B., Recent advances in shuttle effect inhibition for lithium sulfur batteries. Energy Storage Materials 2019, 23, 707-732.

4. He, Y.; Chang, Z.; Wu, S.; Zhou, H., Effective strategies for long-cycle life lithium-sulfur batteries. Journal of Materials Chemistry A 2018, 6 (15), 6155-6182.

5. Wang, M.; Xia, X.; Zhong, Y.; Wu, J.; Xu, R.; Yao, Z.; Wang, D.; Tang, W.; Wang, X.; Tu, J., Porous Carbon Hosts for Lithium-Sulfur Batteries. Chemistry-A European Journal 2019, 25 (15), 3710-3725.

6. Borchardt, L.; Oschatz, M.; Kaskel, S., Carbon materials for lithium sulfur batteries-Ten critical questions. Chemistry-A European Journal 2016, 22 (22), 73247351. 
7. Wu, J.; Pan, Z.; Zhang, Y.; Wang, B.; Peng, H., The recent progress of nitrogendoped carbon nanomaterials for electrochemical batteries. Journal of Materials Chemistry A 2018, 6 (27), 12932-12944.

8. Pang, Q.; Kundu, D.; Cuisinier, M.; Nazar, L., Surface-enhanced redox chemistry of polysulphides on a metallic and polar host for lithium-sulphur batteries. Nature communications 2014, 5, 4759.

9. Liu, X.; Huang, J. Q.; Zhang, Q.; Mai, L., Nanostructured metal oxides and sulfides for lithium-sulfur batteries. Advanced materials 2017, 29 (20), 1601759.

10. He, J.; Manthiram, A., A review on the status and challenges of electrocatalysts in lithium-sulfur batteries. Energy Storage Materials 2019, 20, 55-70.

11. Chen, W.; Lei, T.; Wu, C.; Deng, M.; Gong, C.; Hu, K.; Ma, Y.; Dai, L.; Lv, W.; He, W., Designing Safe Electrolyte Systems for a High - Stability Lithium - Sulfur Battery. Advanced Energy Materials 2018, 8 (10), 1702348.

12. Yuan, H.; Huang, J. Q.; Peng, H. J.; Titirici, M. M.; Xiang, R.; Chen, R.; Liu, Q.; Zhang, Q., A review of functional binders in lithium-sulfur batteries. Advanced Energy Materials 2018, 8 (31), 1802107.

13. Jeong, Y. C.; Kim, J. H.; Nam, S.; Park, C. R.; Yang, S. J., Rational design of nanostructured functional interlayer/separator for advanced $\mathrm{Li}-\mathrm{S}$ batteries. Advanced Functional Materials 2018, 28 (38), 1707411.

14. He, Y.; Qiao, Y.; Zhou, H., Recent advances in functional modification of separators in lithium-sulfur batteries. Dalton Transactions 2018, 47 (20), 6881-6887.

15. Rana, M.; Li, M.; Huang, X.; Luo, B.; Gentle, I.; Knibbe, R., Recent advances in separators to mitigate technical challenges associated with re-chargeable lithium sulfur batteries. Journal of materials chemistry A 2019, 7 (12), 6596-6615.

16. Li, F.; Kaiser, M. R.; Ma, J.; Guo, Z.; Liu, H.; Wang, J., Free-standing sulfurpolypyrrole cathode in conjunction with polypyrrole-coated separator for flexible Li-S batteries. Energy Storage Materials 2018, 13, 312-322.

17. Ma, G.; Huang, F.; Wen, Z.; Wang, Q.; Hong, X.; Jin, J.; Wu, X., Enhanced performance of lithium sulfur batteries with conductive polymer modified separators. Journal of Materials Chemistry A 2016, 4 (43), 16968-16974.

18. He, Y.; Chang, Z.; Wu, S.; Qiao, Y.; Bai, S.; Jiang, K.; He, P.; Zhou, H., Simultaneously Inhibiting Lithium Dendrites Growth and Polysulfides Shuttle by a Flexible MOF - Based Membrane in Li - S Batteries. Advanced Energy Materials 2018, 8 (34), 1802130.

19. Yang, Y.; Zhang, J., Highly Stable Lithium - Sulfur Batteries Based on Laponite Nanosheet - Coated Celgard Separators. Advanced Energy Materials 2018, 8 (25), 1801778.

20. He, J.; Chen, Y.; Manthiram, A., Vertical Co 9 S 8 hollow nanowall arrays grown on a Celgard separator as a multifunctional polysulfide barrier for highperformance Li-S batteries. Energy \& Environmental Science 2018, 11 (9), 2560-2568.

21. Sun, J.; Sun, Y.; Pasta, M.; Zhou, G.; Li, Y.; Liu, W.; Xiong, F.; Cui, Y., Entrapment of polysulfides by a black - phosphorus - modified separator for lithium sulfur batteries. Advanced materials 2016, 28 (44), 9797-9803.

22. Wang, H.; Zhang, W.; Liu, H.; Guo, Z., A Strategy for Configuration of an Integrated Flexible Sulfur Cathode for High - Performance Lithium - Sulfur Batteries. Angewandte Chemie International Edition 2016, 55 (12), 3992-3996.

23. Huang, J.-Q.; Zhuang, T.-Z.; Zhang, Q.; Peng, H.-J.; Chen, C.-M.; Wei, F., Permselective graphene oxide membrane for highly stable and anti-self-discharge lithium-sulfur batteries. Acs Nano 2015, 9 (3), 3002-3011. 
24. Zeng, F.; Jin, Z.; Yuan, K.; Liu, S.; Cheng, X.; Wang, A.; Wang, W.; Yang, Y.s., High performance lithium-sulfur batteries with a permselective sulfonated acetylene black modified separator. Journal of Materials Chemistry A 2016, 4 (31), 12319-12327. 25. Chung, S. H.; Han, P.; Singhal, R.; Kalra, V.; Manthiram, A., Electrochemically stable rechargeable lithium-sulfur batteries with a microporous carbon nanofiber filter for polysulfide. Advanced Energy Materials 2015, 5 (18), 1500738.

26. Tan, L.; Li, X.; Wang, Z.; Guo, H.; Wang, J.; An, L., Multifunctional Separator with Porous Carbon/Multi - Walled Carbon Nanotube Coating for Advanced LithiumSulfur Batteries. ChemElectroChem 2018, 5 (1), 71-77.

27. Song, J.; Zhang, C.; Guo, X.; Zhang, J.; Luo, L.; Liu, H.; Wang, F.; Wang, G., Entrapping polysulfides by using ultrathin hollow carbon sphere-functionalized separators in high-rate lithium-sulfur batteries. Journal of Materials Chemistry A 2018, 6 (34), 16610-16616.

28. Chung, S. H.; Manthiram, A., High-performance Li-S batteries with an ultralightweight MWCNT-coated separator. Journal of Physical Chemistry Letters 2014, 5 (11), 1978-1983.

29. Chung, S. H.; Manthiram, A., Bifunctional separator with a light-weight carboncoating for dynamically and statically stable lithium-sulfur batteries. Advanced Functional Materials 2014, 24 (33), 5299-5306.

30. Chung, S. H. D.; Han, P.; Singhal, R.; Kalra, V.; Manthiram, A., Electrochemically Stable Rechargeable Lithium-Sulfur Batteries with a Microporous Carbon Nanofiber Filter for Polysulfide. Advanced Energy Materials 2015, 5 (18), 1500738 .

31. Balach, J.; Jaumann, T.; Klose, M.; Oswald, S.; Eckert, J.; Giebeler, L., Functional Mesoporous Carbon-Coated Separator for Long-Life, High-Energy LithiumSulfur Batteries. Advanced Functional Materials 2015, 25 (33), 5285-5291.

32. Peng, H. J.; Wang, D. W.; Huang, J. Q.; Cheng, X. B.; Yuan, Z.; Wei, F.; Zhang, Q., Janus separator of polypropylene-supported cellular graphene framework for sulfur cathodes with high utilization in lithium-sulfur batteries. Advanced Science 2015, 3 (1), 1500268 .

33. Schuster, J.; He, G.; Mandlmeier, B.; Yim, T.; Lee, K. T.; Bein, T.; Nazar, L. F., Spherical ordered mesoporous carbon nanoparticles with high porosity for lithiumsulfur batteries. Angewandte Chemie - International Edition 2012, 51 (15), 3591-3595.

34. Tang, K.; Fu, L.; White, R. J.; Yu, L.; Titirici, M. M.; Antonietti, M.; Maier, J., Hollow carbon nanospheres with superior rate capability for sodium-based batteries. Advanced Energy Materials 2012, 2 (7), 873-877.

35. Pang, Q.; Tang, J.; Huang, H.; Liang, X.; Hart, C.; Tam, K. C.; Nazar, L. F., A Nitrogen and Sulfur Dual-Doped Carbon Derived from Polyrhodanine@Cellulose for Advanced Lithium-Sulfur Batteries. Advanced Materials 2015, 27 (39), 6021-6028.

36. Niu, S.; Lv, W.; Zhou, G.; He, Y.; Li, B.; Yang, Q. H.; Kang, F., N and S codoped porous carbon spheres prepared using 1-cysteine as a dual functional agent for high-performance lithium-sulfur batteries. Chemical Communications 2015, 51 (100), 17720-17723.

37. Diez, N.; Ferrero, G. A.; Sevilla, M.; Fuertes, A. B., A simple and general approach for in situ synthesis of sulfur-porous carbon composites for Lithium-Sulfur batteries. Sustainable Energy Fuels 2019, 3, 3498-3509.

38. Lee, S.; Shin, K.-Y.; Jang, J., Enhanced magnetorheological performance of highly uniform magnetic carbon nanoparticles. Nanoscale 2015, 7 (21), 9646-9654. 
39. Fuertes, A. B.; Ferrero, G. A.; Diez, N.; Sevilla, M., A green route to highsurface area carbons by chemical activation of biomass-based products with sodium thiosulfate. ACS Sustainable Chemistry \& Engineering 2018, 6 (12), 16323-16331.

40. Patel, M. U.; Demir - Cakan, R.; Morcrette, M.; Tarascon, J. M.; Gaberscek, M.; Dominko, R., Li - S Battery Analyzed by UV/Vis in Operando Mode. ChemSusChem 2013, 6 (7), 1177-1181.

41. Sevilla, M.; Diez, N.; Ferrero, G. A.; Fuertes, A. B., Sustainable supercapacitor electrodes produced by the activation of biomass with sodium thiosulfate. Energy Storage Materials 2019, 18, 356-365.

42. Evers, S.; Nazar, L. F., Graphene-enveloped sulfur in a one pot reaction: a cathode with good coulombic efficiency and high practical sulfur content. Chemical Communications 2012, 48 (9), 1233-1235.

43. Ji, L.; Rao, M.; Aloni, S.; Wang, L.; Cairns, E. J.; Zhang, Y., Porous carbon nanofiber-sulfur composite electrodes for lithium/sulfur cells. Energy \& Environmental Science 2011, 4 (12), 5053-5059.

44. Li, G.; Sun, J.; Hou, W.; Jiang, S.; Huang, Y.; Geng, J., Three-dimensional porous carbon composites containing high sulfur nanoparticle content for highperformance lithium-sulfur batteries. Nature communications 2016, 7, 10601.

45. Ward, A. T., Raman spectroscopy of sulfur, sulfur-selenium, and sulfur-arsenic mixtures. The Journal of Physical Chemistry 1968, 72 (12), 4133-4139.

46. Balach, J.; Singh, H. K.; Gomoll, S.; Jaumann, T.; Klose, M.; Oswald, S.; Richter, M.; Eckert, J.; Giebeler, L., Synergistically Enhanced Polysulfide Chemisorption Using a Flexible Hybrid Separator with $\mathrm{N}$ and $\mathrm{S}$ Dual-Doped Mesoporous Carbon Coating for Advanced Lithium-Sulfur Batteries. ACS Applied Materials and Interfaces 2016, 8 (23), 14586-14595.

47. Zhou, G.; Paek, E.; Hwang, G. S.; Manthiram, A., Long-life Li/polysulphide batteries with high sulphur loading enabled by lightweight three-dimensional nitrogen/sulphur-codoped graphene sponge. Nature Communications 2015, 6, 7760.

48. Hippauf, F.; Nickel, W.; Hao, G. P.; Schwedtmann, K.; Giebeler, L.; Oswald, S.; Borchardt, L.; Doerfler, S.; Weigand, J. J.; Kaskel, S., The importance of pore size and surface polarity for polysulfide adsorption in lithium sulfur batteries. Advanced Materials Interfaces 2016, 3 (18), 1600508.

49. Borchardt, L.; Oschatz, M.; Kaskel, S., Tailoring porosity in carbon materials for supercapacitor applications. Materials Horizons 2014, 1 (2), 157-168.

50. Zhang, S. S., Liquid electrolyte lithium/sulfur battery: Fundamental chemistry, problems, and solutions. Journal of Power Sources 2013, 231, 153-162.

51. Cui, Y.; Wu, X.; Wu, J.; Zeng, J.; Baker, A. P.; Lu, F.; Liang, X.; Ouyang, J.; Huang, J.; Liu, X., An interlayer with architecture that limits polysulfides shuttle to give a stable performance Li-S battery. Energy Storage Materials 2017, 9, 1-10.

52. Zhu, J.; Ge, Y.; Kim, D.; Lu, Y.; Chen, C.; Jiang, M.; Zhang, X., A novel separator coated by carbon for achieving exceptional high performance lithium-sulfur batteries. Nano Energy 2016, 20, 176-184.

53. Su, Y.-S.; Manthiram, A., Lithium-sulphur batteries with a microporous carbon paper as a bifunctional interlayer. Nature communications 2012, 3, 1166.

54. Kong, W.; Yan, L.; Luo, Y.; Wang, D.; Jiang, K.; Li, Q.; Fan, S.; Wang, J., Ultrathin $\mathrm{MnO} 2 /$ Graphene Oxide/Carbon Nanotube Interlayer as Efficient Polysulfide - Trapping Shield for High - Performance Li - S Batteries. Advanced Functional Materials 2017, 27 (18), 1606663. 
55. Su, Y.-S.; Manthiram, A., A new approach to improve cycle performance of rechargeable lithium-sulfur batteries by inserting a free-standing MWCNT interlayer. Chemical communications 2012, 48 (70), 8817-8819.

56. Balach, J.; Jaumann, T.; Klose, M.; Oswald, S.; Eckert, J. r.; Giebeler, L., Mesoporous carbon interlayers with tailored pore volume as polysulfide reservoir for high-energy lithium-sulfur batteries. the Journal of Physical Chemistry C 2015, 119 (9), $4580-4587$.

57. Hwang, J. Y.; Kim, H. M.; Lee, S. K.; Lee, J. H.; Abouimrane, A.; Khaleel, M. A.; Belharouak, I.; Manthiram, A.; Sun, Y. K., High - Energy, High - Rate, Lithium Sulfur Batteries: Synergetic Effect of Hollow TiO2 - Webbed Carbon Nanotubes and a Dual Functional Carbon - Paper Interlayer. Advanced Energy Materials 2016, 6 (1), 1501480 .

58. Zhang, Z.; Wang, G.; Lai, Y.; Li, J.; Zhang, Z.; Chen, W., Nitrogen-doped porous hollow carbon sphere-decorated separators for advanced lithium-sulfur batteries. Journal of Power Sources 2015, 300, 157-163.

59. Yang, J.; Chen, F.; Li, C.; Bai, T.; Long, B.; Zhou, X., A free-standing sulfurdoped microporous carbon interlayer derived from luffa sponge for high performance lithium-sulfur batteries. Journal of Materials Chemistry A 2016, 4 (37), 14324-14333.

60. Chung, S. H.; Chang, C. H.; Manthiram, A., Progress on the Critical Parameters for Lithium-Sulfur Batteries to be Practically Viable. Advanced Functional Materials 2018, 1801188. 
For Table of Contents Only
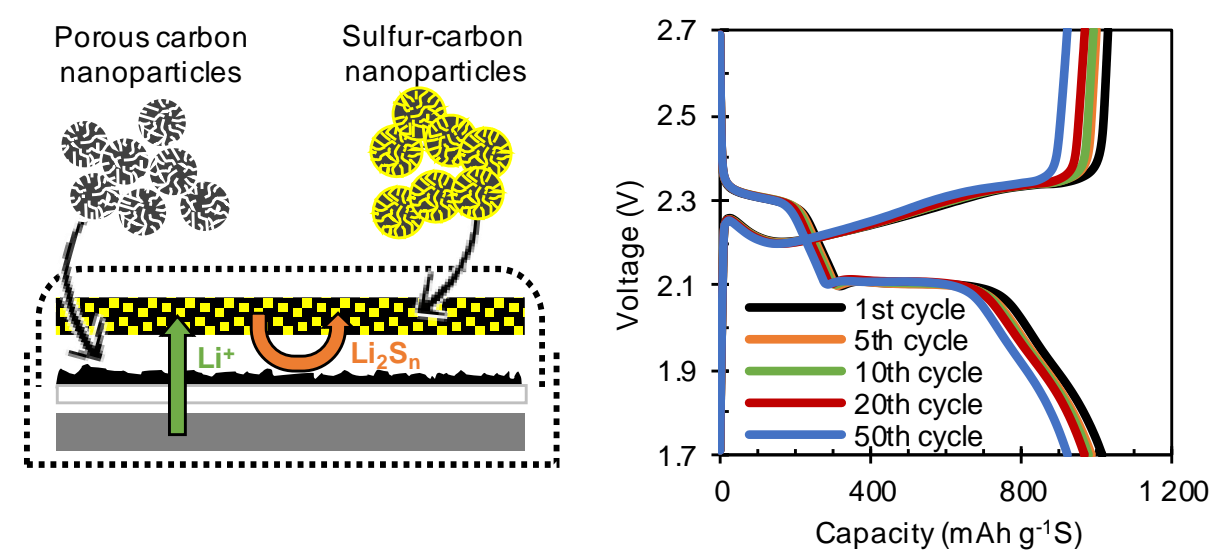